\title{
Molecular and behavioral changes associated with adult hippocampus-specific SynGAP1 knockout
}

\author{
Mary Muhia, ${ }^{1,5}$ Silvia Willadt, ${ }^{2}$ Benjamin K. Yee, ${ }^{1,6}$ Joram Feldon, ${ }^{1}$ Jean-Charles Paterna, ${ }^{1}$ \\ Severin Schwendener, ${ }^{1}$ Kaspar Vogt, ${ }^{2}$ Mary B. Kennedy, ${ }^{3}$ and Irene Knuesel ${ }^{4,7}$ \\ ${ }^{1}$ Laboratory of Behavioral Neurobiology, Swiss Federal Institute of Technology, CH-8063 Schwerzenbach, Switzerland; ${ }^{2}$ Biozentrum, \\ University of Basel, CH4056 Basel, Switzerland; ${ }^{3}$ Division of Biology, California Institute of Technology, Pasadena, California 91125 , \\ USA; ${ }^{4}$ Institute of Pharmacology and Toxicology, University of Zurich, $\mathrm{CH}-8057$ Zurich, Switzerland
}

\begin{abstract}
The synaptic Ras/Rap-GTPase-activating protein (SynGAPI) plays a unique role in regulating specific downstream intracellular events in response to $\mathrm{N}$-methyl-D-aspartate receptor (NMDAR) activation. Constitutive heterozygous loss of SynGAPI disrupts NMDAR-mediated physiological and behavioral processes, but the disruptions might be of developmental origin. Therefore, the precise role of SynGAPI in the adult brain, including its relative functional significance within specific brain regions, remains unexplored. The present study constitutes the first attempt in achieving adult hippocampal-specific SynGAP1 knockout using the Cre/loxP approach. Here, we report that this manipulation led to a significant numerical increase in both small and large GluAl and NR1 immunoreactive clusters, many of which were non-opposed to presynaptic terminals. In parallel, the observed marked decline in the amplitude of spontaneous excitatory currents (sEPSCS) and interevent intervals supported the impression that SynGAPI loss might facilitate the accumulation of extrasynaptic glutamatergic receptors. In addition, SynGAPI-mediated signaling appears to be critical for the proper integration and survival of newborn neurons. The manipulation impaired reversal learning in the probe test of the water maze and induced a delay-dependent impairment in spatial recognition memory. It did not significantly affect anxiety or reference memory acquisition but induced a substantial elevation in spontaneous locomotor activity in the open field test. Thus, the present study demonstrates the functional significance of SynGAPI signaling in the adult brain by capturing several changes that are dependent on NMDAR and hippocampal integrity.
\end{abstract}

The brain-specific synaptic Ras/Rap GTPase-activating protein (SynGAP1) is highly enriched at the glutamatergic postsynaptic density (PSD) (Kennedy 1997, 2000) and is coupled to the NMDAR complex by the scaffolding proteins PSD-95 and SAP102 (Chen et al. 1998; Kim et al. 1998). It is highly enriched in the cortex and hippocampus, with weak expression in the cerebellum (Kim et al. 1998). Following NMDAR activation, SynGAP1 is phosphorylated by $\mathrm{Ca}^{2+} /$ calmodulin-dependent kinase II ( $\alpha$ CaMKII) (Krapivinsky et al. 2004; Oh et al. 2004), whereupon it negatively regulates Ras and Rap GTPase activity and their respective downstream signaling cascades (Chen et al. 1998; Kim et al. 1998; Krapivinsky et al. 2004; Pena et al. 2008). Functionally, SynGAP1 loss triggers extensive neuronal apoptosis (Knuesel et al. 2005) and precocious clustering of PSD-95, NMDA, and AMPA receptors at glutamatergic synapses (Kim et al. 2003; Vazquez et al. 2004; Rumbaugh et al. 2006; Carlisle et al. 2008). The loss of SynGAP1 is associated with alterations in complex behavior and cognitive processes including learning and memory. We and others have recently shown that constitutive heterozygous SynGAP1 deficiency produces multiple behavioral phenotypes ranging from hyperactivity, anxiolysis, cognitive deficits, to altered sensi-

Present addresses: ${ }^{5}$ University Medical Center Hamburg-Eppendorf Center for Molecular Neurobiologie Hamburg, Protein Trafficking and Synapse Formation Falkenried 94, 20251 Hamburg, Germany; ${ }^{6}$ Robert Stone Dow Neurobiology Laboratories, Legacy Research Institute, 1225 NE 2nd Avenue, Portland, OR 97232, USA ${ }^{7}$ Corresponding author.

E-mail knuesel@pharma.uzh.ch.

Article is online at http://www.learnmem.org/cgi/doi/10.1101/lm.026351.112. tivity to psychomimetics (Guo et al. 2009; Muhia et al. 2009, 2010).

To date, the relevance of SynGAP1 to the genesis and maintenance of synapses has been demonstrated primarily in neuronal cultures obtained from homozygous SynGAP1 knockout embryos. Likewise, in vivo analyses have so far been carried out in constitutive heterozygous knockout mice. Although meaningful, one cannot exclude the possible contribution by developmental mechanisms. Hence, the precise functional significance of SynGAP1 in the postnatal/adult nervous system remains ill-defined. In line with its fundamental role during development, complete SynGAP1 deletion is associated with premature death (Komiyama et al. 2002; Kim et al. 2003; Vazquez et al. 2004; Knuesel et al. 2005; Barnett et al. 2006). To dissociate developmental from adult functions, one feasible approach is to induce a region-specific conditional knockout in adult animals. This allows us to circumvent the homozygous lethality and to identify the significance of SynGAP1 in synaptic function within discrete regions of the adult brain. The present study is the first to achieve a selective Syngap1 gene ablation in the adult hippocampus. We used the Cre-loxP approach by utilizing recombinant adeno-associated virus (rAAV) vectors as a tool to deliver functional Cre (cyclization recombination) to hippocampal cells. rAAV vectors are known to transduce both dividing and non-dividing cells in vivo, and the tranduced cells can be observed up to 6 mo post-injection without indication of apoptosis or inflammatory changes (Kaspar et al. 2002; Paterna and Bueler 2002; Di Pasquale et al. 2003; Ahmed et al. 2004; Paterna et al. 2004). Here, adult homozygous SynGAP1 floxed ( $\mathrm{SG}^{\text {flox/flox }}$ ) mice received bilateral intra-hippocampal 
injections of either control (rAAV-EGFP) or Cre recombinase-expressing (rAAV-EGFP-Cre) viral vector constructs. The spatially restricted nature of SynGAP1 knockout allowed us to examine (1) its functional relevance to hippocampal morphology using immunohistochemistry, (2) NMDAR-mediated synaptic transmission using whole-cell recordings from transfected neurons, and (3) impact on NMDAR- and hippocampal-mediated functions across several cognitive and non-cognitive behavioral tasks.

\section{Results}

\section{Efficient transduction of hippocampal neurons using rAAV vectors}

Four weeks following rAAV vector microinfusion, a clear and selective transduction efficacy was evident and highly restricted to the hippocampus (Fig. 1B,C). The EGFP expression profile was
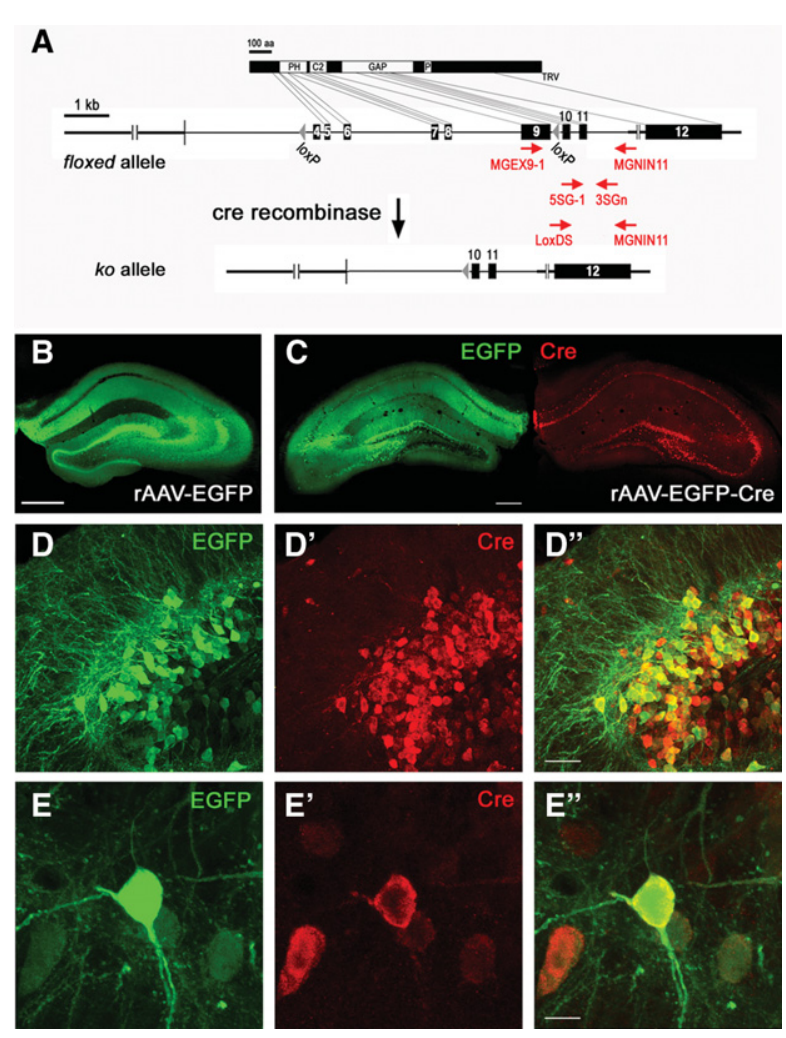

Figure 1. Efficient and localized transduction of rAAV vectors. (A) Schematic representation of the SynGAP1 floxed $\left(S^{\text {flox }}\right.$ ) allele. The $S G^{\text {flox/flox }}$ mutant line harbors two LoxP sites flanking exons 4-9 of the SynGAP1 gene coding sequence. Cre-mediated knockout of LoxP-flanked SynGAP1 gene sequence occludes the transcription of all four SynGAP1 isoforms (Vazquez et al. 2004; Knuesel et al. 2005). (Red) Primers used for nested PCR to confirm Cre recombinase-mediated gene deletion. (B) Low-magnification mosaic fluorescence image depicting a strong and hippocampus-specific expression profile of EGFP in rAAV-EGFP mice 4 wk post-intrahippocampal viral vector delivery. (C) Coimmunofluorescence staining showing the prominent dendritic EGFP signal (green, left) and somatic anti-Cre (red, right) immunoreactivity in both dentate gyrus (DG) granule cells and pyramidal neurons in the hippocampus after rAAV-EGFP-Cre injection. (D) Higher magnification of granule cells in the DG showed prominent EGFP labeling and anti-Cre immunoreactivity. (E) Antigen retrieval using pepsin pre-treatment allowed optimal visualization of Cre-positive cells yet reduced surface EGFP signals, leading to partial colocalization of the two proteins. Scale bars, (B) $500 \mu \mathrm{m}$; (C) $300 \mu \mathrm{m} ;(D) 30 \mu \mathrm{m} ;(E) 8 \mu \mathrm{m}$. prominent in the DG granule cell layer, hilus, CA4, and CA3 pyramidal cell layer subfields. CA1 pyramidal cells were sparsely labeled despite a strong detection of the EGFP signal in the axonal and dendritic compartments of the stratum oriens and radiatum (Fig. 1B). However, further verification by application of antiCre antibody revealed extensive colocalization of Cre recombinase and EGFP (Fig. 1D,E) and robust Cre labeling in cells from all hippocampal subfields (Fig. 1C). There was no evidence for anti-Cre IR in rAAV-EGFP (control) transduced cells (data not shown), thereby confirming the specificity of the immunohistochemical findings.

Moreover, dual-immunofluorescence labeling of brain sections using an antibody against the astrocytic marker, GFAP revealed no immunoreactivity (IR) in EGFP-positive cells (Fig. 2A$\left.\mathrm{A}^{\prime \prime}\right)$. Thus, the rAAV vector transduction appeared neuronalspecific.

\section{rAAV vector expression of Cre recombinase results in efficient deletion of the floxed SynGAPI gene sequence}

To determine the efficiency of Cre-mediated gene recombination, we isolated EGFP-positive cells from the CA and DG hippocampal subfields by means of laser microdissection. As depicted in Figure 2, B and C, transduced single cells expressing EGFP were outlined and laser pressure-catapulted (LPC) into the cap of Microfuge vials. Successful cell extraction and capturing were confirmed by epifluorescence and phase-contrast microscopy of the tissue section and caps, respectively. Subsequent nested PCR reactions of the isolated genomic DNA from the collected cells confirmed Cre-mediated recombination and deletion of the LoxP-flanked SynGAP1 gene sequence (Fig. 2D).

\section{Cre-mediated gene recombination leads to a significant reduction of hippocampal SynGAPI levels}

To examine the impact of Cre-mediated recombination on SynGAP1 at the protein level, we performed immunohistochemical stainings with an antibody designed against all SynGAP1 isoforms. Qualitative histological analysis of immunoperoxidaseprocessed brain sections revealed a substantial reduction of SynGAP1 IR in the hippocampi of rAAV-EGFP-Cre mice compared with controls (Fig. 3A-D). This was particularly prominent in the DG dendritic and the CA1-CA4 subfields. Densitometrical analysis of the DAB reaction product yielded significant reductions of SynGAP1 1R in rAAV-EGFP-Cre mice in CA1 stratum radiatum $(-23.8 \%, P<0.001)$, CA3 stratum radiatum $(-42.1 \%$, $P<0.05)$, and CA4 stratum radiatum $(-35 \%, P<0.01)$ compared with control mice. Notably, GABAergic interneurons in rAAVEGFP-Cre injected mice were still positive for SynGAP1 staining (Fig. 3C, $\mathrm{D}^{\prime \prime}$ ).

\section{Absence of toxic effects from rAAV vector delivery}

Transgene expression did not appear to exert any toxicity to the transduced cells as evidenced by a clearly intact neuronal morphology and the presence of numerous dendritic spines (Fig. 2A). In addition, anti-Iba-1 IR, a marker for activated microglia, was indistinguishable between that of rAAV-EGFP-Cre and rAAV-EGFP controls (Fig. 3E,F). We did not observe any changes in the ramifications nor in the cell bodies of microglia in rAAV-EGFP-Cre tissue, suggesting the absence of rAAV-induced inflammation or degeneration. Further confirmation by optical densitometrical analysis of the Iba-1 IR did not yield any statistically significant difference between rAAV-EGFP (rel. $\mathrm{OD}_{\mathrm{Hip}}=33.31 \pm$ 2.94) and rAAV-EGFP-Cre (rel. $\mathrm{OD}_{\mathrm{Hip}}=33.76 \pm 4.47 ; P=0.93$ ) brain sections. 

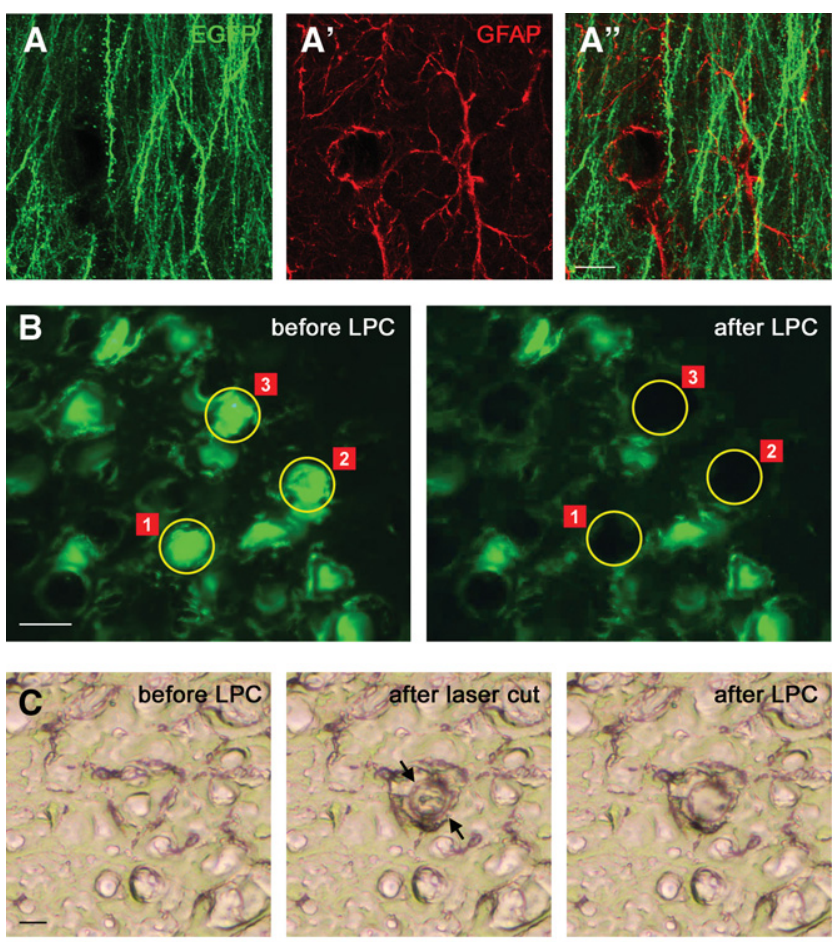

D

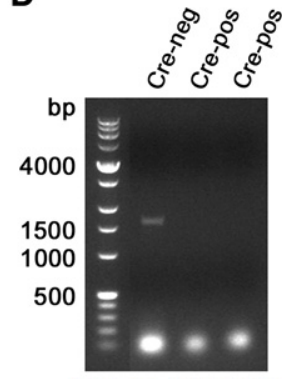

MGEX9-1/MGIN11

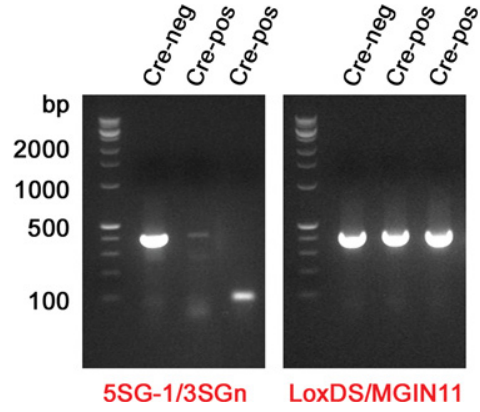

Figure 2. Efficient Cre-mediated SynGAP1 gene recombination. $(A)$ Neuronal-specific rAAV vector-mediated transduction. Representative high-magnification images of rAAV-EGFP expressing neuronal dendrites in the DG molecular layer. Anti-GFAP immunostaining $\left(A^{\prime}\right.$, red) and merged image $\left(A^{\prime \prime}\right)$ shows the tight neuron-astrocyte association but no colocalization of the two cell types. (B) Epifluorescence images depicting EGFP-positive neurons before and after successful LPC removal. (C) Phase-contrast images show the typical trace of the nitrogen laser (337 nm) following microdissection (arrows) and the empty space thereafter. $(D)$ Following rAAV vector delivery, efficient Cre-mediated recombination leads to complete deletion of the LoxP-flanked SynGAP1 gene sequence. (Left) First-stage PCR of genomic DNA from Cre recombinasenegative (and EGFP-negative) (lane 1) and -positive (lanes 2, 3) hippocampal neurons using the MGEX9-I/MGIN11 primer pair. Lane 1 (no recombination) renders a $\sim 1800-b p$ PCR band, which is not detectable in Cre-expressing EGFP-positive cells, where the binding sequence of MGEX9-1 is absent following Cre-mediated recombination. (Middle, second-stage PCR) PCR products from first-stage PCR were combined with the 5SG-1/3SGn primer pair. A 400-bp PCR product was detected from genomic DNA of Cre recombinase-negative neurons (lane 1, no recombination), but was either undetectable (lane 3 ) or weakly present (lane 2), indicating efficient in vivo SynGAP1 gene recombination. (Right) Confirmation of the presence of the LPC-isolated and extracted genomic DNA in all samples; first-stage PCR was performed using the LoxDS/MGINII primer pair, which binds with the SynGAP1 gene irrespective of the recombination status. A strong diagnostic 400-bp PCR product was detected in all lanes, indicating the presence of genomic DNA in all samples. Scale bars, $10 \mu \mathrm{m}$.

\section{Cre recombination of the floxed SynGAP1 gene sequence is associated with alterations in glutamatergic receptor expression}

SynGAP1 plays a critical role in synaptogenesis and spine morphology during development and adulthood as shown by in vitro and in situ experiments involving either cultured neurons obtained from $\mathrm{SG}^{-/-}$embryos (Kim et al. 2003; Vazquez et al. 2004; Rumbaugh et al. 2006) or brain slices from adult heterozygous $\mathrm{SG}^{+/-}$mice (Carlisle et al. 2008). Here, brain sections obtained from experimentally naive rAAV-EGFP-Cre- and rAAVEGFP-injected mice were processed for anti-NR1 and anti-GluA1 immunohistochemistry to examine the impact of conditional adult hippocampus SynGAP1 knockout on NMDA and AMPA receptor clustering and distribution. Brief pepsin pre-treatment allowed optimal visualization of both glutamate receptor subtypes in DG and CA dendritic subfields as shown by the representative image of the DG molecular layer in rAAV-EGFP-injected mice (Fig. 4A).

GluA1-immunoreactive puncta were closely associated with EGFP-filled neurites, likely representing glutamatergic synapses on dendritic spines (Fig. 4A"). An increase in GluA1-positive cluster size was observed in rAAV-EGFP-Cre injected tissue compared with the control mice. Statistical analyses of the densitometrical evaluations of the size and the brightness (expressed as integrated pixel density) of GluA1-immunoreactive clusters in the hippocampus confirmed these observations and revealed a significant increase following SynGAP1 deletion in the DG molecular layer (ml) (Student's $t$-test, $t=-6.3, P<0.001)$, CA1 stratum radiatum $(\mathrm{sr})(t=-2.2, P=0.025)$, CA3 sr $(t=-4.6$, $P<0.001$ ), and lucidum (sl) $(t=-6.3, P<0.001)$ (Fig. 4C). Similarly, statistical comparison of the cluster size distribution yielded a significant treatment effect for the DG $\mathrm{ml}$ (KS-test, $\left.d f=2, D_{\max }=0.05, \chi^{2}=107.31, P<0.0001\right)$, CA3 sr $(d f=2$, $\left.D_{\max }=0.02, \chi^{2}=16.4, P<0.001\right)$, and sl $\left(d f=2, D_{\max }=0.04\right.$, $\left.\chi^{2}=29.8, P<0.0001\right)$, indicating an overall shift toward larger clusters in rAAV-EGFP-Cre mice compared with controls. In CA1 sr, differences in cluster size distribution between treatment groups only approached significance (KS-test, $d f=2, D_{\max }=$ $0.02, \chi^{2}=6.1, P=0.09$ ). The analysis also revealed a prominent increase in the number of small GluA1-positive clusters (size range from 0.02 to $0.1 \mu \mathrm{m}^{2}$ ) in hippocampal brain sections of rAAV-EGFP-Cre compared with control mice (DGml, KS-test, $d f=2, D_{\max }=0.02, \chi^{2}=6.1, P=0.006$ ) (Fig. 4C), suggesting an increase in the number of newly formed glutamatergic synapses.

Highly similar results were obtained using anti-NR1 immunohistochemistry. Double-fluorescence microscopy revealed a positive association of NR1-immunoreactivity with EGFP-positive dendrites in both DG and CA subfields (data not shown). The NR1-postive clusters were significantly enlarged in rAAVEGFP-Cre mice compared with rAAV-EGFP controls, resulting in a significant increase in the area and size of NR1-immunoreactive signals (integrated pixel brightness) in the DG $\mathrm{ml}$ $(t=-3.1, P=0.002)$, CA1 sr $(t=-4.6, P<0.001)$, and CA3 sr $(t=3.2, P=0.002)$. Statistical comparison between the two treatment groups yielded a significant shift of the cumulative size distribution curve toward larger values in rAAV-EGFP-Cre versus control subjects (KS-test, DG $\mathrm{ml}, d f=2, D_{\max }=0.02, \chi^{2}=9.06$, $P=0.02$; CA3 sr, $d f=2, D_{\max }=0.02, \chi^{2}=10.4, P=0.01$; CA1 sr, $d f=2, D_{\max }=0.04, \chi^{2}=50.0, P<0.001$ ) (Fig. 4C). These findings suggest that conditional hippocampus-specific SynGAP1 knockout might lead to elevated glutamatergic synapse formation, including abnormal insertion of NMDA and AMPA receptors. 

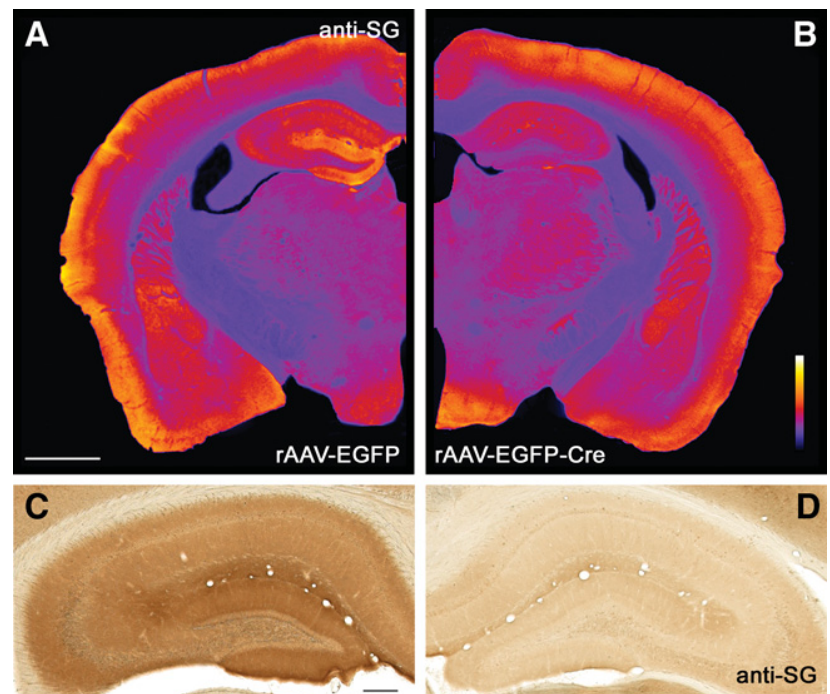
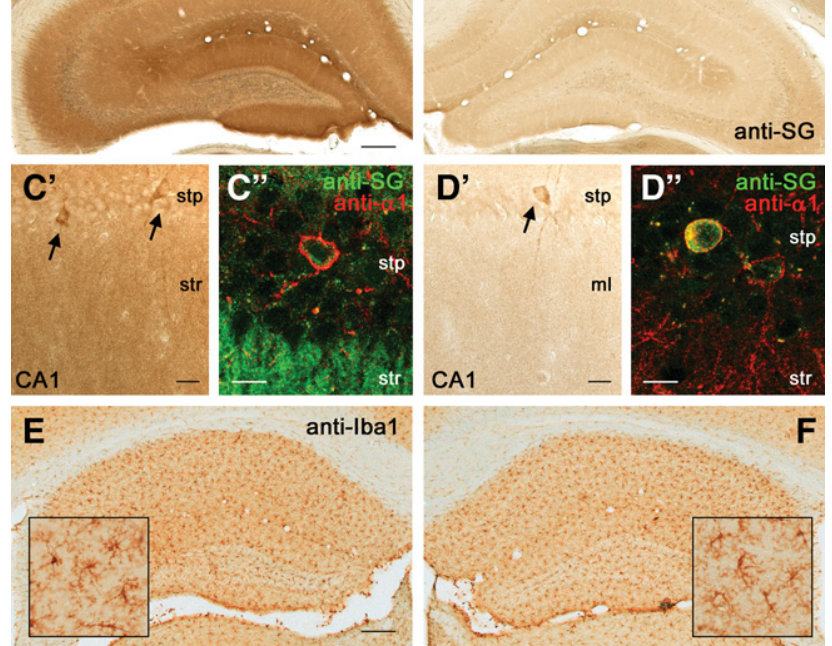

Figure 3. Conditional deletion of the $S G^{\text {flox }}$ allele results in a significant loss of SynGAP1 immunoreactivity in the hippocampus. $(A, B)$ Representative images of coronal brain sections processed for anti-SynGAP1 immunohistochemistry. The images have been color-coded for visual display; (yellow-white) the strongest immunoreactivity; (dark purple/black) background levels. Note the selective reduction in SynGAP1 following intrahippocampal delivery of the rAAV-EGFP-Cre virus. $(C, D)$ Higher-magnification images of the immunoperoxidase staining of SynGAP1 in the dorsal hippocampus of rAAV-EGFP $(C)$ and rAAV-EGFP-Cre $(D)$ injected mice 4 wk post-intrahippocampal viral vector delivery. A significant reduction in SynGAP1 immunoreactive signal was evident throughout the hippocampus, particularly prominent in the DG and CA dendritic fields. Residual SynGAP1 immunoreactivity was detected in GABAergic neurons expressing the $\mathrm{GABA}_{\mathrm{A}}$ receptor $\alpha 1$ subunit in the CA1 stratum pyramidale (stp, arrows), representing non-transduced interneurons in rAAV-EGFP-Cre $\left(D^{\prime}, D^{\prime \prime}\right)$ compared with control mouse brain sections $\left(C^{\prime}, C^{\prime \prime}\right)$. (E,F) Immunoperoxidase staining using the microglial marker lba1 on hippocampal brain sections of rAAV-EGFP $(E)$ and rAAV-EGFP-Cre $(F)$ injected mice. Note the absence of microglial activation following intrahippocampal viral vector delivery. (ml) Molecular layer; (str) stratum radiatum. Scale bars, $(A) 1 \mathrm{~mm} ;(C, E) 200 \mu \mathrm{m} ;\left(C^{\prime}, D^{\prime}\right) 20 \mu \mathrm{m}$; $\left(C^{\prime \prime}, D^{\prime \prime}\right) 10 \mu \mathrm{m}$.

\section{Functional alterations in glutamatergic neurotransmission associated with SynGAP1 knockout}

The abnormal increase in size and number of GluA1- and NR1-positive synaptic clusters suggested that the absence of SynGAP1 might have an impact on glutamatergic neurotransmission. We investigated this by performing whole-cell patch-clamp recordings of CA1 neurons of hippocampal slices obtained from $S G^{\text {flox/flox }}$ mice 4 wk after unilateral delivery of rAAV-EGFP-Cre$(n=4)$ or rAAV-EGFP-injected mice $(n=3)$. Both the frequency and amplitude of spontaneous excitatory post-synaptic currents
(sEPSCs) were analyzed using three to six slices per animal. The non-injected hippocampus served as internal control. Statistical comparisons between control and injected hemispheres revealed a significant reduction in the sEPSC amplitude (KS-test: $D_{\max }=$ $0.2, P<0.001$ ) (Fig. 5A). This was accompanied by an increase in sEPSC frequency as shown by the significant decrease in interevent intervals (KS-test: $D_{\max }=0.3, P<0.001$ ) (Fig. 5B), likely related to the observed increase in numerical density of small NR1/ GluA1-immunoreactive clusters. Recordings using control viral vectors did not reveal significant differences between the two hemispheres (data not shown).

Post hoc immunohistochemical analyses were performed to verify ipsilateral and contralateral hemispheres and to confirm the impact of SynGAP1 deletion on glutamatergic receptor localization and density. In line with our semi-quantitative evaluation of the NR1/GluA1 immunoreactivity between treatment groups, the qualitative immunohistochemical analysis following the electrophysiological recordings confirmed a substantial enlargement of NR1- and GluA1-positive clusters following SynGAP1 deletion. Coimmunofluorescence staining using anti-NR1 or GluA1 in combination with anti-VGlut1 (vesicular glutamate transporter 1) revealed that the abnormally large glutamate receptor clusters were not opposed to VGlut1 terminals (Fig. 5C,D). This observation suggested that the enlargement of NR1- and GluA1-immunoreactive clusters may stem from extrasynaptic accumulation of glutamate receptors, which might underlie the reduced sEPSC amplitude.

\section{Reduction in DCX-positive neurons following conditional SynGAP1 deletion}

Based on our previous observation of a significant reduction in the number of newborn neurons in the DG subgranular zone of heterozygous SynGAP1 knockout $\left(\mathrm{SG}^{+/-}\right.$) mice (Muhia et al. 2010), we investigated whether the absence of SynGAP1 in our conditional knockout model might lead to abnormal survival and integration of adult newborn neurons in the hippocampal circuitry. Immunohistochemical staining using an antibody against doublecortin (DCX), an endogenous marker for newborn neurons (Couillard-Despres et al. 2005), revealed a very low numerical density of DCX-positive neurons in rAAV-EGFP-Cre- compared with rAAV-EGFP-injected mice (Fig. 6C-E). Statistical analysis revealed a significant reduction of DCX-positive neurons in rAAV-EGFPCre mice compared with controls (ANOVA, $F_{(1,14)}=42.87, P<$ 0.0001 ). There was an overall increase in the number of DCX-positive newborn cells coexpressing activated caspase-3 (Fig. 6B), indicating elevated apoptotic loss of newly formed neurons in rAAVEGFP-Cre-injected versus control mice. Interestingly, DCX-positive neurons were also found in the hilar region following deletion of the floxed Syngap1 gene (Fig. 6D), a phenomenon not observed in rAAV-EGFP controls, suggesting that reduced SynGAP1 expression and accompanying reduction in glutamatergic neurotransmission result in abnormal migration and reduced survival of newborn neurons.

\section{Behavioral characteristics of hippocampal-specific SynGAP1 knockout}

The morphological and electrophysiological findings prompted us to examine the behavioral impact of this manipulation on hippocampal and NMDAR-dependent tests, which had revealed marked learning deficits in constitutive heterozygous SynGAP1 knockout mice (Muhia et al. 2010). The results are presented according to the outcome of the cognitive tests due to their significance and relevance to the nature of the manipulation rather than in chronological order. 

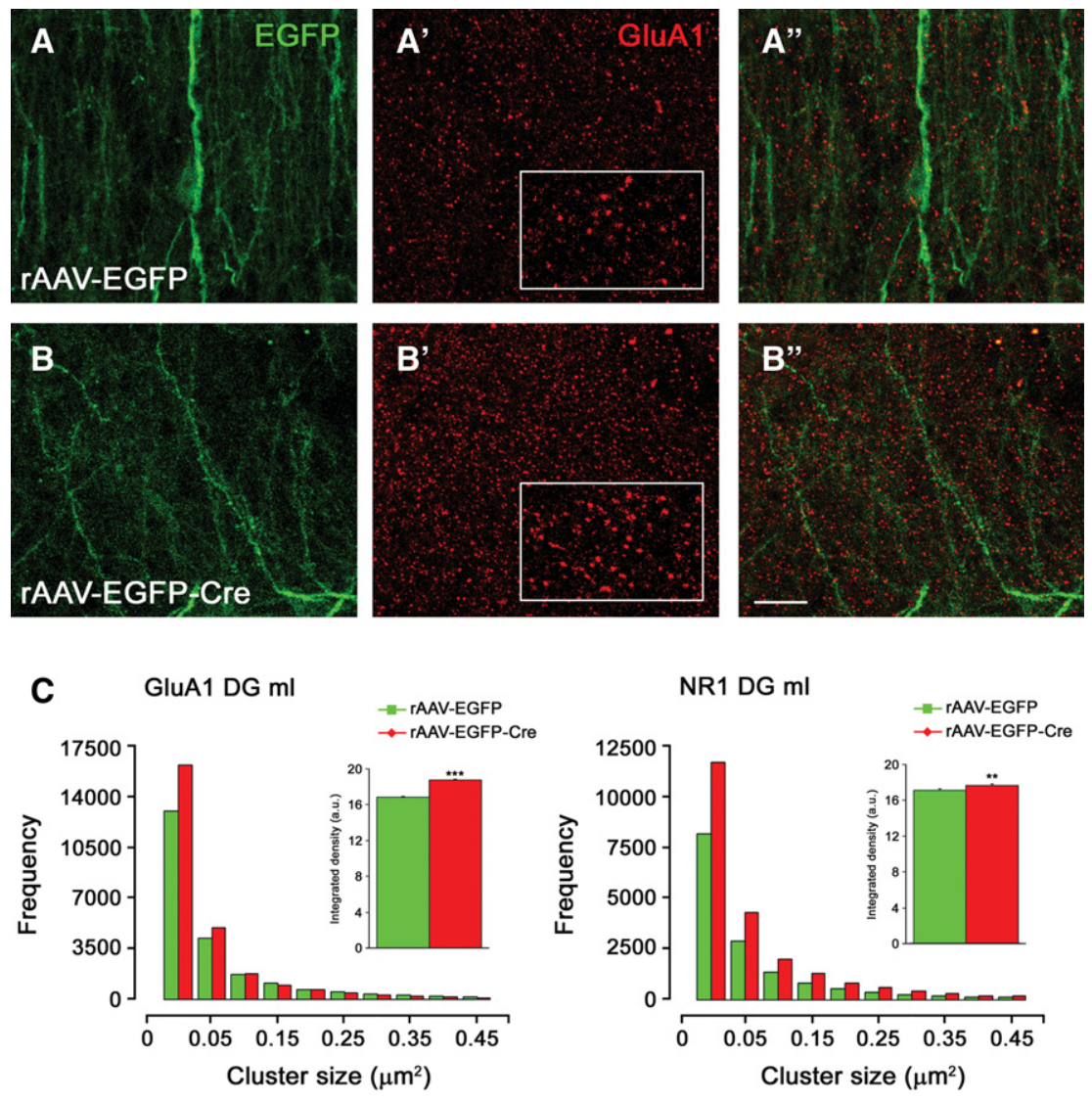

Figure 4. Ablation of the $S C^{f l o x}$ allele leads to an increase in number and size of GluR1- and NR1-positive clusters. ( $A$ ) Double-fluorescence images acquired in the DG molecular layer of brain sections from rAAV-EGFP $\left(A-A^{\prime \prime}\right)$ and rAAV-EGFP-Cre injected mice $\left(B-B^{\prime \prime}\right)$. (Green staining) EGFP-filled dendrites of viral-transduced granule cells; (red staining) anti-GluR1 staining in the same field of view. The boxes in $A^{\prime}$ and $B^{\prime}$ show an enlarged view of the molecular layer with distinct immunoreactive signals, which likely represent glutamatergic synapses on dendritic spines. (C) Quantitative analysis of the cluster size distribution revealed significant differences between the two treatment groups, both with respect to the frequency of small clusters $\left(<0.05 \mu \mathrm{m}^{2}\right)$ as well as the integrated pixel brightness of individual immunoreactive puncta, pointing to the elevation of newly formed and at the same time enlargement of existing glutamatergic synapses/spines in rAAV-EGFP-Cre mice compared with the control group. Statistics based on two-sample Kolmogorov-Smirnov and Mann-Whitney U-test. Scale bar, $10 \mu \mathrm{m}$.

\section{Morris water maze task}

\section{Visible cued test performance}

Mice were first familiarized to the basic water maze escape procedure in order to examine for changes in motivation as well as sensory and motor (visual and swimming) function. Both treatment groups readily learned the escape response (Fig. 7A,B), with performance improving across the four trials (latency: $F_{(3,90)}=5.78, P<0.001$; path length: $\left.F_{(3,90)}=10.12, P<0.001\right)$. Although a main effect of Treatment did not achieve statistical significance in the analysis of average swim speed, a significant Treatment-by-Sex interaction $\left(F_{(1,30)}=6.13, P<0.05\right)$ emerged, as a consequence of a sex-dependent effect on swim speed: SynGAP1 deletion in the hippocampus reduced swim speed in the male mice $(\mathrm{rAAV}-\mathrm{EGFP}=16.3 \pm 1.2$ vs. rAAV-EGFP-Cre $=$ $13.3 \pm 1.1 \mathrm{~cm} / \mathrm{sec}$ ) but enhanced it in the female (rAAV-EGFP $=$ $14.2 \pm 1.2$ vs. rAAV-EGFP-Cre $=16.7 \pm 1.1 \mathrm{~cm} / \mathrm{sec}$ ). This suggested to us that the escape latency measure might not be an effective unbiased index of performance, and therefore the path length measure (being independent of speed) is chosen here as the performance measure.

\section{Reference memory: acquisition}

Here, the fixed escape platform location allowed for gradual improvement in performance, which was accompanied by subsequent development of spatial bias for the target location. Across the $8 \mathrm{~d}$ of training, both treatment groups improved in acquisition and showed a progressive decline in path length (Fig. 7C, Acquisition). Consistent with this impression, a $2 \times 2 \times 8$ (Treatment $\times$ Sex $\times$ Days) split-plot ANOVA of path length yielded a highly significant main effect of Days $\left(F_{(7,210)}=5.48, P<\right.$ $0.001)$. The analysis also yielded a trend toward increased path length in the rAAV-EGFP-Cre mice $\left(F_{(1,30)}=3.10, P=\right.$ $0.089)$, although the critical Treatmentby-Days interaction term did not approach significance $(F<1)$. Additional analyses restricted to the first trial of each day yielded only a significant effect of Day $\left(F_{(7,210)}=6.46, P<0.001\right)$, suggesting successful retention abilities for the platform's spatial location during acquisition.

\section{Probe test 1}

A probe test was performed $24 \mathrm{~h}$ after the last acquisition trial, in which the platform was removed from the pool and the mice were allowed to swim for 60 sec. To gauge the spatial search strategy, we examined the proportion of percentage path length in the target quadrant relative to the other quadrants (Fig. 7D). A $2 \times 2 \times 4$ (Treatment $\times$ Sex $\times$ Quadrants) ANOVA of percentage path length yielded a main effect of Quadrants $\left(F_{(3,90)}=6.38, P<0.01\right)$, which suggested efficient retention of the platform's spatial location. Although both treatment groups showed a preference for the target quadrant, this bias appeared weaker in the rAAV-EGFP-Cre mice compared with controls (Fig. 7D). We therefore performed a onesample $t$-test for the target quadrant against chance level performance (25\%). It revealed that whereas the rAAV-EGFP control mice exceeded chance level preference for the target quadrant $(P<0.05)$, the rAAV-EGFP-Cre mice failed to do so $(P=0.09)$.

\section{Reversal learning}

Next, the hidden platform was switched to the opposite quadrant to assess the animal's ability to learn a novel platform location against interference from the previously acquired memory trace of the former platform location. The initial impact of reversal was apparent in both treatment groups (Fig. 7C, Reversal). This impression was examined by comparing the last day of acquisition training (day 8) against the first day of reversal (day 10), which revealed a near-significant effect of Days $\left(F_{(1,30)}=4.04, P=0.05\right)$. However, there was little improvement in escape performance over the $6 \mathrm{~d}$ of reversal training (Fig. 7C). A $2 \times 2 \times 6$ (Treatment $\times$ Sex $\times$ Days) split-plot ANOVA of path length failed to yield any indication of inter-day improvement. No other significant main effects or interactions emerged. 
A
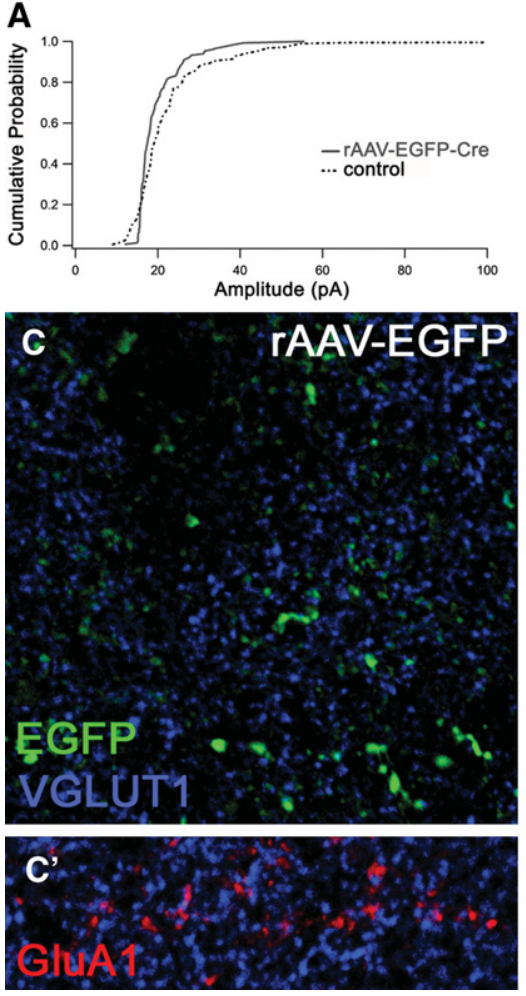

B
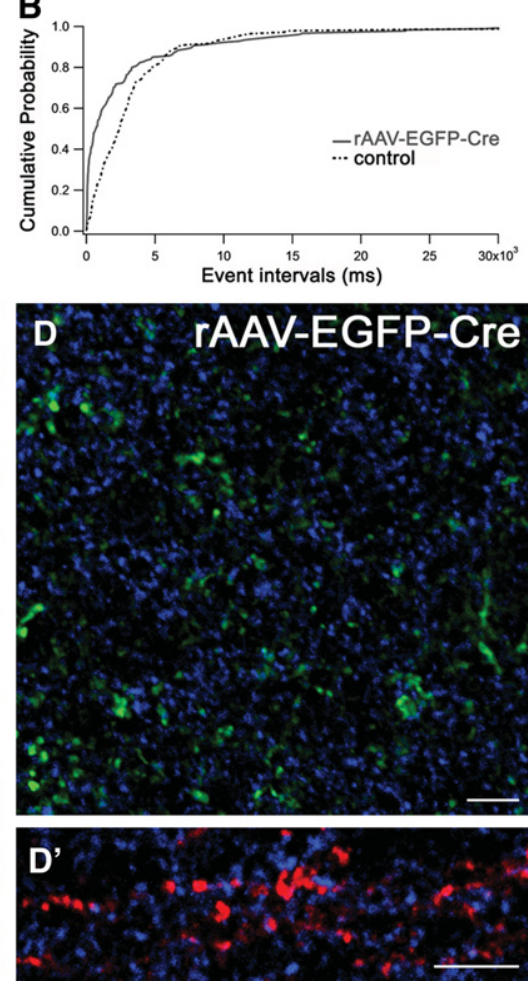

Figure 5. Hippocampus-specific loss of SynGAP1 alters excitatory neurotransmission. Whole-cell voltage-clamp recordings of spontaneous excitatory events were performed in acute brain slices at $4 \mathrm{wk}$ post-virus injection. $(A, B)$ Cumulative probability distribution of the amplitudes $(A)$ and inter-event intervals $(B)$ measured in the ipsilateral and contralateral (control) hemisphere of rAAV-EGFP-Cre-injected mice. $(C, D)$ Post hoc immunohistochemical analyses revealed a marked increase in extrasynaptic glutamate receptors on the ipsilateral versus contralateral hippocampus as shown by the increase in anti-GluR1 immunoreactive clusters that were not opposed to presynaptic glutamatergic (positive for vesicular glutamate transporter, VGlut1) terminals (enlarged view in $D^{\prime}$ ). Scale bars, $5 \mu \mathrm{m}$.

\section{Probe test 2}

Nevertheless, when the probe test was introduced $24 \mathrm{~h}$ after the last reversal trial, rAAV-EGFP control mice showed a distinct spatial preference for the novel target quadrant, indicating retention of the novel platform location. However, rAAV-EGFP-Cre mice failed to show an equivalent preference and appeared to search more in the former target location (Fig. 7E). A $2 \times 2 \times 4$ (Treatment $\times$ Sex $\times$ Quadrants) ANOVA of percentage path length yielded a main effect of Quadrants $\left(F_{(3,90)}=3.93, P<0.05\right)$ and a marginally significant Treatment-by-Quadrant interaction $\left(F_{(3,90)}=2.44, P=0.07\right)$. The latter was examined further by ANOVA restricted to each treatment group followed by pairwise comparisons. In the control group, the analysis revealed a significant main effect of Quadrant $\left(F_{(3,42)}=5.65, P<0.01\right)$ and significant difference between the target and opposite previously reinforced quadrant $(P<0.05)$. Preference for the target quadrant exceeded chance level (25\%) performance following an additional one-sample $t$-test $(P<0.05)$. None of these measures attained significance in the analysis for rAAV-EGFP-Cre mice.

\section{Delay-dependent deficit in spatial recognition memory in the Y-maze}

We also examined the short-term memory of recent exposure to a spatial location by assessing spatial novelty preference in the Y-maze task (Sanderson et al. 2007; Bannerman et al. 2008). In the sample phase, both treatment groups performed similarly in terms of the time spent exploring the start and familiar arms. There were no statistically significant main effects or interactions. However, across all delay intervals, rAAV-EGFP-Cre mice showed increased locomotor activity compared with rAAVEGFP controls $\left(F_{(1,30)}=6.77, P<0.05\right)$. In the test phase conducted subsequently, both treatment groups demonstrated a preference to explore the previously not-visited (i.e., novel) arm $\left(F_{(1,60)}=\right.$ 4.97, $P<0.05$ ) in a $2 \times 2 \times 2 \times 3$ (Treatment $\times$ Sex $\times$ Arms $\times$ Delays) ANOVA of time spent in each arm. The analysis also yielded a significant two-way interaction between Treatment and Delay $\left(F_{(2,60)}=4.45, P<0.05\right)$, which was examined further by performing ANOVAs restricted to each delay interval. A significant Treatmentby-Arms interaction emerged at the 1-h delay condition $\left(F_{(1,30)}=6.07, P<0.05\right)$. Subsequent post hoc comparisons indicated that this effect stemmed from a significant decrease in the exploration of the novel arm by rAAV-EGFP-Cre mice compared with controls $\left(F_{(1,30)}=6.05, \quad P<0.05\right)$. Consistent with previous observations in the sample phase, rAAV-EGFP-Cre mice showed significantly enhanced locomotor activity compared with the rAAV-EGFP control mice $\left(F_{(1,30)}=13.15\right.$, $P<0.01$ ). Similarly, a $2 \times 2 \times 3$ (Treatment $\times$ Sex $\times$ Delay) ANOVA of percent time spent in the novel arm yielded a significant Treatment $x$ Delay interaction $\left(F_{(2,60)}=3.53, P<0.05\right)$. Subsequent post hoc analysis revealed that this interaction stemmed from significantly less exploration of the novel arm by the rAAV-EGFP-Cre mice in the 1-h delay interval (Fig. 8B) $\left(F_{(1,30)}=6.72, P<0.05\right)$.

\section{Anxiety-related behavior and locomotor activity}

To examine the impact of hippocampus-specific SynGAP1 knockout in the non-cognitive domain, we assessed the performance of rAAV-EGFP-Cre mice in the elevated plus maze test of anxiety. As indicated above, this test was performed when animals were behaviorally naive. A tendency toward increased anxiety was seen in rAAV-EGFP-Cre mice compared with controls. The mean percentage time spent in the open arms for the rAAV-EGFP-Cre and rAAV-EGFP control mice was $26.1 \pm 7.1 \mathrm{sec}$ and $41.6 \pm 7.5 \mathrm{sec}$, respectively. Likewise, the mean percentage of entries into the open arms was as follows: rAAV-EGFP-Cre (33.6 \pm $6.1)$ and rAAV-EGFP controls $(47.1 \pm 6.4)$. Statistical analysis, however, failed to yield a significant group effect in terms of either percentage open arm entries or percentage time spent in the open arms (\% Frequency: $F_{(1,30)}=2.31, P=0.14$; \% Time: $F_{(1,30)}=2.25, P=$ $0.15)$.

In the open field, the rAAV-EGFP-Cre mice showed a substantial and consistent elevation in locomotor activity compared with control subjects (Fig. 8A), as evidenced by a split-plot (Treatment $\times$ Sex $\times$ Bins) ANOVA, which yielded a significant effect of Treatment $\left(F_{(1,30)}=4.77, P<0.05\right)$. A gradual reduction in activity as a function of time was evident from the main effect of Bins $\left(F_{(5,150)}=40.68, P<0.01\right)$.

\section{Discussion}

The present study investigated for the first time the functional impact of adult hippocampus-specific SynGAP1 gene deletion and provides evidence for SynGAP1 function in adult synaptic 

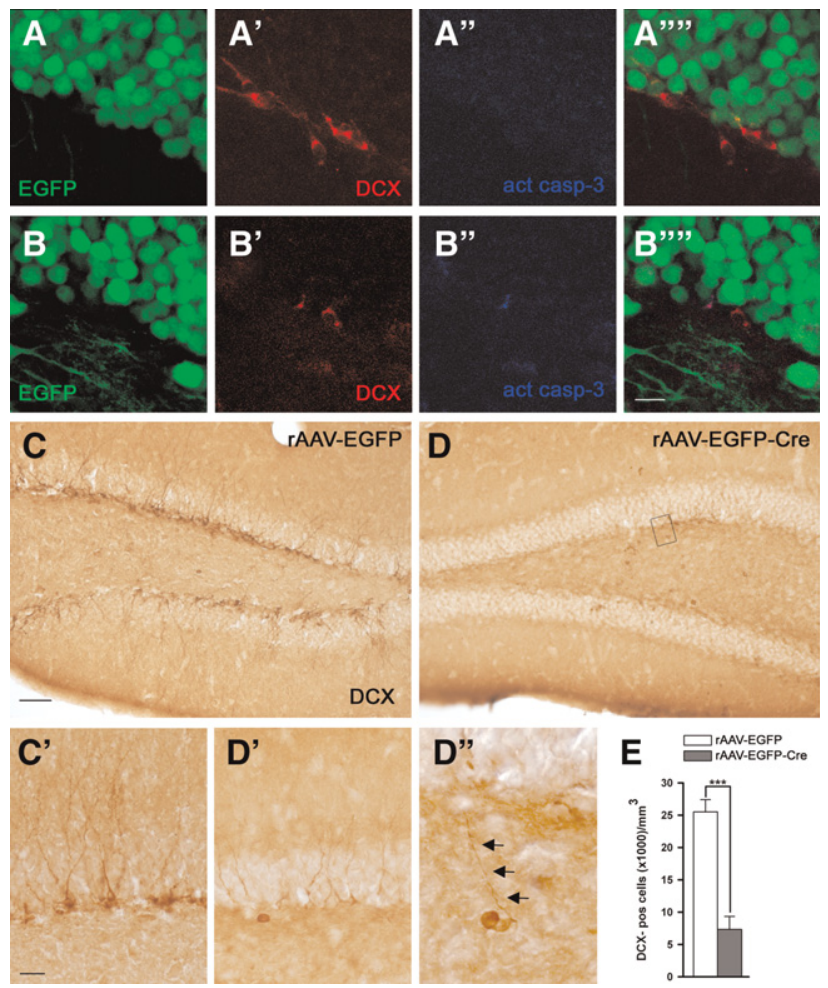

Figure 6. Cre recombinase-mediated ablation of the $\mathrm{SG}^{\text {flox }}$ allele prevents the formation of new born neurons. $(A, B)$ Triple-fluorescence images taken from the dentate gyrus subgranular layer of rAAV-EGFP- $(A)$ and rAAV-EGFP-Cre-injected $(B)$ mice. (Green staining) Transduced dentate gyrus granule cells; (red staining) the same field of view with anti-DCX staining, characteristically localized to the DG subgranular zone. The presence of apoptotic neurons was examined using an antibody against activated caspase-3 (blue), a key player in executing apoptotic signals. ( $C-D)$ Anti-DCX immunohistochemical staining to visualize newly generated neurons in the adult dentate gyrus (DG). rAAV-EGFPCre-injected mice $(D)$ show a significantly lower number of $D C X$-positive cells in the subgranular zone of the DG compared with rAAV-EGFP-injected mice $(C)$. $\left(C^{\prime}, D^{\prime}\right)$ Enlarged view of the granule cell layer of the corresponding treatment groups. $\left(D^{\prime \prime}\right)$ Note the presence of ectopic DCX-positive cells in the hilus of rAAV-EGFP-Cre subjects. (E) Quantification of the total number of DCX-positive cells. $\left.{ }^{* * *}\right) P<0.0001$. Scale bars, $10 \mu \mathrm{m}$.

function. The restricted nature of the manipulation was sufficient to induce significant modifications in hippocampal morphology and its mediated neurophysiological and behavioral functions. These changes comprised a significant increase in the numerical density of synaptic glutamate receptors, their enlargement at extrasynaptic sites, and corresponding changes in excitatory neurotransmission. Furthermore, we showed a reduction in the number of DG newborn neurons and demonstrated several changes in cognitive and non-cognitive behavioral functions following this manipulation.

Here, rAAV vector expression was restricted to the dorsal and ventral hippocampus. The serotypes used (5/2 and 8/2) preferentially targeted neurons with no indication of astroglial transduction, reactive gliosis, or evidence of toxicity. This observation complements multiple studies that have used comparable titers of rAAV-Cre vectors (Kaspar et al. 2002; Scammell et al. 2003; Ahmed et al. 2004; Paterna et al. 2007). We demonstrated efficient and focal deletion of the floxed coding sequence by PCR of isolated genomic DNA from transduced cells. Despite a concomitant significant decrease in SynGAP1 protein levels, we did not observe a complete loss in the hippocampus. This may stem from low
SynGAP1 protein turnover levels, which have yet to be established. Transduction of GABAergic interneurons also appeared limited as evidenced by few remaining SynGAP1-positive cells. This phenomenon is not surprising given that prior studies using viral Cre recombinase delivery showed pronounced but not complete deletion of the floxed alleles (Scammell et al. 2003; Inturrisi 2005; Glass et al. 2008; Lee et al. 2008). Nonetheless, the viral vector-mediated Cre recombinase delivery applied here yielded a highly efficient and consistent genetic deletion across subjects compared with the more variable gene deletion efficiency using other, conditional breeding strategies (Knuesel et al. 2005).

\section{Neuroanatomical and neurophysiological phenotypes}

The observed significant increase in the number and size of GluA1- and NR1-immunoreactive clusters parallels prior in vitro studies demonstrating that SynGAP1 loss induces precocious glutamatergic synapse formation, presumably due to aberrant recruitment of synaptic AMPA and NMDA receptors (Krapivinsky et al. 2004; Vazquez et al. 2004; Rama et al. 2008). Vazquez et al. (2004) reported that SynGAP1 knockout triggers earlier synapse and spine formation, which ultimately become larger compared with controls. Hence, it is plausible that the increase of smaller GluA1- and NR1-positive clusters seen here might be indicative of elevated synapse formation, while the larger clusters could represent abnormalities in synapse maturation and accumulation of extrasynaptic receptors. In line with this view, our electrophysiological data revealed a significant increase in inter-event intervals of excitatory postsynaptic currents, further confirming the elevation of synaptic glutamate receptors. On the other hand, the amplitudes of the postsynaptic currents were significantly decreased in SynGAP1 knockout slices compared with controls and were indeed accompanied by a pronounced increase in extrasynaptic glutamate receptors. These findings partially complement a recent study showing a substantial increase in number and head volume of large mushroom spines in hippocampal pyramidal cells of adult SynGAP ${ }^{+/-}$mice (Carlisle et al. 2008). However, the same study did not report a genotypic effect with respect to numerical density and morphology of stubby and thin protrusions, which likely represent less-mature spines. One interpretation is that while the loss of a single SynGAP1 allele may be sufficient to perturb spine morphology, a complete or near complete loss of both copies is required to induce/accelerate synapse formation.

It has been shown that changes in AMPA receptor surface expression stem from disturbances of the SynGAP1-ERK signaling cascade (Rumbaugh et al. 2006). This biochemical event is shown to critically determine glutamate receptor surface expression and regulate spine dynamics (Gao et al. 2011). Collectively, it is conceivable that the SynGAP1-mediated signaling pathway essential for glutamatergic synapse formation during development may play a similar role in adulthood by controlling synapse number and morphology, as well as adaptive synaptic changes involving synaptic glutamate receptor insertion.

Finally, in line with previous findings (Muhia et al. 2010), decreased hippocampal neurogenesis suggested a role for SynGAP1 in neuronal survival and integration of newborn neurons. This might be expected given that SynGAP1 mediates the Ras-ERK signaling cascade; a key modulator of multiple effects of neurotrophic factors, including neuronal differentiation, proliferation, and survival (Kaplan and Miller 2000; Huang and Reichardt 2003). Additionally, our observed colocalization of activated caspase-3 with some of the DCX cells concurs with previous observations of increased apoptotic cell death following conditional SynGAP1 knockout in the developing brain and adult DG (Knuesel et al. 2005). One possible explanation for this might be linked to SynGAP1's regulation of n-cofilin activity and its 
A

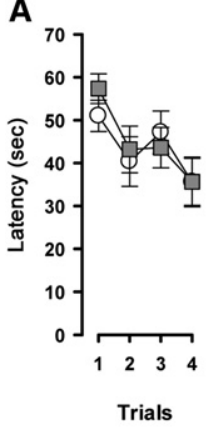

B
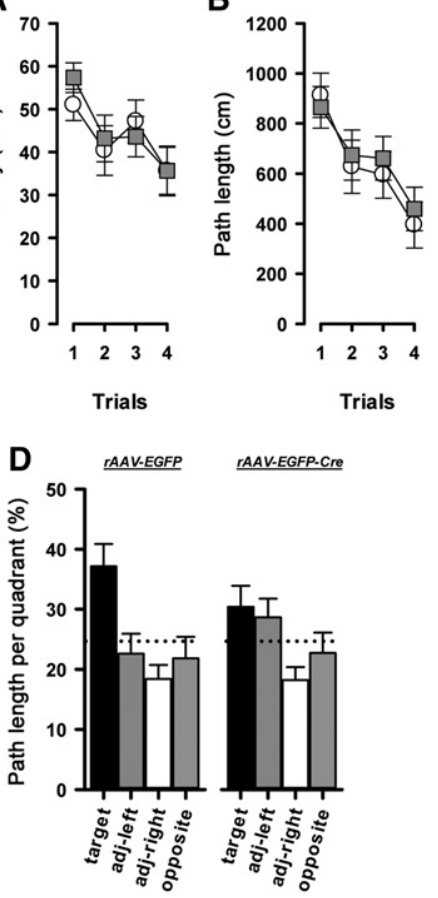

Probe test 1

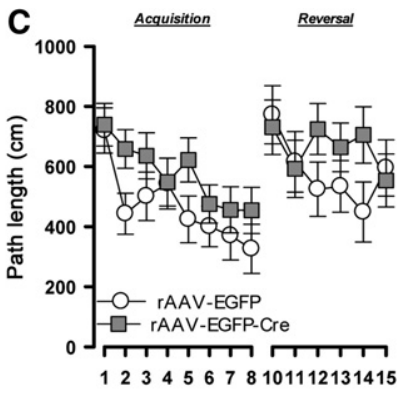

Days

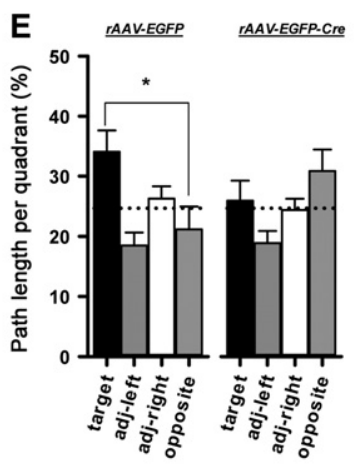

Probe test 2

Figure 7. Spatial reference memory and reversal learning in the Morris water maze task. Both treatment groups acquired the visible platform task across trials based on escape latency $(A)$ and path length $(B)$. (C) Acquisition: Both treatment groups showed progressive decline in path length across training. Reversal: Performance when the platform was shifted to the opposite target quadrant. $(D)$ In probe test 1 , both treatment groups showed preference for the target quadrant, although this appeared less pronounced in the rAAV-EGFP-Cre mice compared with controls. $(E)$ In probe test 2 after reversal, rAAV-EGFP-Cre mice failed to show preference for the new target quadrant. Dotted line depicts chance Chance level performance (at 25\%). Values are expressed as mean \pm SEM; $\left(^{*}\right) P<0.05$.

modulation of F-actin depolymerization in mature spines. Loss of SynGAP1 leads to prolonged n-cofilin phosphorylation, which interferes with F-actin assembly, subsequently leading to actin cytoskeleton stabilization (Carlisle et al. 2008). Interestingly, recent findings confirm that forebrain-specific deletion of n-cofilin and its associated loss in synaptic actin dynamics leads to associative learning impairments (Rust et al. 2010). Hence, it is plausible that SynGAP1 deficiency significantly impairs spine morphology and motility, thereby disrupting excitatory synapse function that is fundamental for proper migration and integration of newborn neurons into neuronal circuits (Aimone et al. 2010). The observation of several DCX-positive neurons in the hilus and expression of activated caspase- 3 by some of these cells indeed suggests abnormal migration and integration of newborn neurons following loss of SynGAP1 signaling.

\section{Mnemonic phenotype}

Although a direct causal link cannot be confirmed here, we can speculate that the ensuing behavioral phenotype might be linked to the significant reductions in hippocampal SynGAP1 protein content and the distinct morphological and electrophysiological changes associated with SynGAP1 disruption.

In the water maze, rAAV-EGFP-Cre mice successfully acquired the reference memory (RM) task and showed preference for the training quadrant. Yet, there was some indication of increased path length, and their preference for the target quadrant was less pronounced than controls. This seems to reflect a less ef$\alpha$ CaMKII function, namely, normal RM acquisition but impaired reversal (Elgersma et al. 2002). Additionally, decreased adult dentate gyrus (DG) neurogenesis leads to deficits in water maze reversal (Garthe et al. 2009). Given that SynGAP1 is highly phosphorylated by $\alpha$ CaMKII (Krapivinsky et al. 2004; Oh et al. 2004), it is plausible that disruption of the SynGAP1- $\alpha$ CaMKII biochemical event, including decreased neurogenesis (Fig. 6) contributes
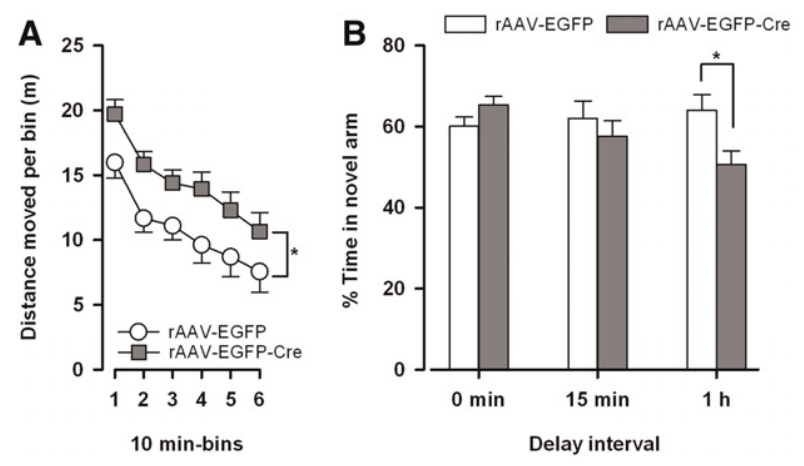

Figure 8. (A) Spontaneous locomotor activity in the open field test expressed as total distance traveled over the 60-min session. (B) Spontaneous spatial alternation in the Y-maze. Preference for the novel arm, as indexed as percent time spent in the novel arm was attenuated in the 1 -h retention interval in rAAV-EGFP-Cre mice; $\left(^{*}\right) P<0.05$. All values are expressed as mean \pm SEM. 
to the reversal deficit seen here. In line with this speculation, SynGAP1 heterozygous knockout mice show decreased DG neurogenesis and gross impairments in the rapid and flexible switching required for working memory function (Muhia et al. 2010).

Deficits in the spontaneous spatial novelty task might be taken as impaired familiarity judgment, which translates to an inability to discriminate familiar over novel arms (Sanderson et al. 2007; Engelhardt et al. 2008). Here, the deficit in rAAV-EGFP-Cre mice emerged only in the longer delay interval, which suggested that hippocampus-specific SynGAP1 knockout is unlikely to interfere with general novelty preference. Yet, it appears from the delaydependent nature of the impairment that SynGAP1 deficiency compromises working memory function when an increase in memory load, in terms of retention interval, is imposed.

\section{Nonmnemonic phenotypes}

A phenotype beyond mnemonic function emerged in the form of enhanced spontaneous locomotor activity in rAAV-EGFP-Cre mice. This is compatible with previous studies in SynGAP1 $1^{+/-}$ mice (Guo et al. 2009; Muhia et al. 2010), further substantiating the robustness of this phenotype, and identifies it as stemming primarily from a loss of hippocampal SynGAP1. Additionally, the hyperactivity phenotype observed here is compatible with known effects of hippocampal damage on locomotor activity (Gray and McNaughton 1983; Pouzet et al. 1999; Deacon et al. 2002; Bannerman et al. 2003; Bast and Feldon 2003).

Consistent with the hypothesis that fear and anxiety are subserved by the septo-hippocampal system (Gray 1982), lesions in the murine ventral hippocampus lead to an anxiolytic phenotype (Bannerman et al. 2004). Anxiety-related behavior did not differ between treatment groups, which contrasted with the anxiolytic phenotype previously reported in SynGAP1 ${ }^{+/-}$mice (Guo et al. 2009; Muhia et al. 2010). This outcome suggests that adult loss of SynGAP1 might not alter anxiety-related behavior when its deletion is restricted to the hippocampus. It is therefore plausible that the anxiolytic phenotype of SynGAP1 $1^{+/-}$mice stems from SynGAP1 disruption outside the hippocampus and/or from changes in developmental mechanisms that manifest later in adulthood. This suggests possible divergent roles of SynGAP1 during development and adulthood in some behavioral functions.

\section{Conclusion}

In summary, we provide the first in vivo evidence for the impact of adult SynGAP1 deficiency on hippocampal morphology, physiology, and hippocampus-dependent cognitive and non-cognitive behavioral processes. Collectively, the anomalous changes indicate that hippocampus-specific SynGAP1 loss is sufficient to alter distinct functions known to depend on NMDAR and hippocampal integrity. We have also shown that changes associated with SynGAP1 deficiency cannot be wholly attributed to its malfunction during development by demonstrating similar features with adult hippocampus SynGAP1 knockout (Komiyama et al. 2002; Guo et al. 2009; Muhia et al. 2009, 2010). SynGAP1 therefore continues to play a critical role in adulthood by possibly mediating similar biochemical cascades following NMDAR activation. This represents a significant step toward a finer delineation of SynGAP1's role in adult synaptic function.

\section{Materials and Methods}

\section{Subjects}

The generation of the SynGAP1 homozygous floxed mice ( $S G^{\text {flox }}$ $f l o x)$ has been described and published elsewhere (Vazquez et al. 2004; Knuesel et al. 2005). Briefly, the transgenic $S G^{\text {flox/flox }}$ line harbors two loxp sites flanking the sequence between exons 4 and 9, which encode the PH, C2, and GAP domains (Fig. 1A). Thus, excision of the loxP-flanked SynGAP1 gene coding sequence by Cre recombinase eliminates all SynGAP1 isoforms (Vazquez et al. 2004). $S G^{\text {flox/flox }}$ mice were back-crossed and maintained in a C57BL/ 6 background. They were bred at our in-house facility (Laboratory of Behavioral Neurobiology, ETH Zurich, Schwerzenbach, Switzerland). At 3 wk of age, the mice were weaned, sexed, and genotyped by PCR of isolated genomic DNA (see Knuesel et al. 2005). They were kept under a reversed light-dark cycle (lights on from 1900 to $0700 \mathrm{~h})$ in a temperature $\left(21^{\circ} \mathrm{C} \pm 1^{\circ} \mathrm{C}\right)$ and humidity $(55 \% \pm 5 \%)$ controlled room. Food (Kliba 3430$)$ and water were available ad libitum. The subjects were singly caged following the surgical procedure (see below) at 8-10 wk of age. For behavioral evaluation, a cohort comprising $34 S G^{f l o x /}$ flox mice received intrahippocampal microinjections of either the control (rAAV-EGFP) viral vectors (eight $S G^{\text {flox/flox }}$ mice per sex) or Cre expressing (rAAV-EGFP-Cre) vectors (nine $S G^{\text {flox }}$ flox mice per sex). We had previously established in a pilot study stable transgene expression, peaking at 4 wk post-microinjection. Hence, behavioral experiments commenced 4 wk post-surgery at 12-14 wk of age and were all performed in the dark phase of the lightdark cycle. An additional behaviorally naive cohort, age-matched against the behaviorally tested cohort, and consisting of $32 S G^{\text {flox/ }}$ flox mice ( $n=8$ per viral vector and sex) underwent a similar surgical procedure and housing conditions. This cohort was destined for immunohistochemical analyses and was sacrificed to coincide with the conclusion of behavioral experiments. A third agematched cohort of mice was prepared for electrophysiological recordings, involving unilateral intrahippocampal injections $(n=$ 3-4 per viral vector). All procedures were performed under experimental approval by the Cantonal Veterinary Office, Zurich (Swiss Animal protection Act, 1978), and conform to the European Council Directives 86/609/EEC on animal experimentation.

\section{Plasmid construction}

The Klenow-blunted SalI-NLS Cre-XbaI fragment of pCMV-NLS Cre was inserted into the Klenow-blunted and HindIII-restricted pEGFP-C1 (Clontech) to generate pEGFP-NLS Cre. Subsequently, the NheI-EGFP-NLS Cre-MluI fragment of pEGFP-NLS Cre was inserted into the NheI-MluI-restricted AAV-2 vector plasmid psub2-hPDGF $\beta$-WPRE (Paterna et al. 2000) to obtain psub-2-hPDGFßEGFP-NLS Cre-WPRE. Oligodeoxynucleotides (Microsynth AG) encoding the 24-amino-acid foot and mouth disease (FMDV) 2A sequence (APVKQTLNFDLLKLAGDVESNPGP) were hybridized and inserted into the NheI-MluI restricted psub-2-hPDGF $\beta$ WPRE to produce psub-2-hPDGFß-2A-WPRE. The PCR-amplified PacI-EGFP-SacI fragment of pEGFP-N1 was inserted into the PacI-SacI-restricted psub-2-hPDGF $\beta$-2A-WPRE upstream and inframe of the FMDV 2A sequence to generate psub-2-hPDGFßEGFP-2A-WPRE. The PCR-amplified SpeI-NLS Cre-MluI fragment of psub-2-hPDGFß-EGFP-NLS Cre-WPRE was then inserted into the SpeI-MluI restricted psub-2-hPDGF 3 -EGFP-2A-WPRE downstream and in-frame from the FMDV $2 \mathrm{~A}$ sequence to generate psub-2-hPDGFß-EGFP-2A-NLS Cre-WPRE. The PCR-amplified PacIAAV-8 cap genes-PmeI fragment of plasmid p5E18-VD2/8 (James Wilson, University of Pennsylvania, PA) was inserted into the PacI-PmeI-restricted hybrid AAV/adenovirus (AV) helper plasmid pJCP-AAV-5 (Pietropaolo et al. 2007) to generate pJCP-AAV-8.

\section{Production, purification, and titration of recombinant adenovirus-associated viral ( $\mathrm{rAAV}$ ) vectors}

We generated the recombinant adenovirus-associated viral (rAAV) vectors by the transient calcium phosphate precipitation method. Briefly, 70\%-80\% confluent human embryonic kidney (HEK) 293 T cells were transfected with a 1.5:1 molar ratio of AAV-2 vector plasmids and hybrid AAV/AV helper plasmids. Forty-eight to $72 \mathrm{~h}$ post-transfection, cells were collected and lysed in AAV lysis buffer $(150 \mathrm{mM} \mathrm{NaCl}, 50 \mathrm{mM}$ Tris- $\mathrm{HCl}$ at $\mathrm{pH}$ 8.5) by three freezethaw cycles. Crude cell lysate was incubated for $30 \mathrm{~min}$ at $37^{\circ} \mathrm{C}$ with Benzonase $(50 \mathrm{U} / \mathrm{mL})$, cleared by low-speed centrifugation, and purified by iodixanol gradient ultracentrifugation 
(Zolotukhin et al. 1999). The rAAV vector-containing fractions were collected, and the iodixanol was removed by $100-\mathrm{kDa}$ ultrafiltration (Vivaspin 20; Sartorius) using phosphate-buffered saline (PBS) containing $1 \mathrm{mM} \mathrm{Mgcl} 2$ and $2.5 \mathrm{mM} \mathrm{KCl} \mathrm{(PBS-MK} \mathrm{buffer).}$ Physical titers (vector genomes per milliliter, vg/mL) were measured by quantitative real-time PCR using primers specific for the simian virus (SV) 40 polyadenylation signal [poly(A)]. Physical titers were estimated at $1 \times 10^{13} \mathrm{vg} / \mathrm{mL}$ for the rAAV vector preparations used in the present study.

\section{Stereotaxic intra-hippocampal injections of rAAV vectors} General anesthesia was achieved by intra-peritoneal (i.p.) injection of the following mixture diluted in $0.9 \%$ Saline: Dormicum (Midazolam, $0.15 \mathrm{mg} / \mathrm{kg} \mathrm{BW}$, Roche Pharma); Domitor (Medetomidin, $15 \mu \mathrm{g} / \mathrm{kg}$ BW, Orion), and Fentanyl (1.5 $\mu \mathrm{g} / \mathrm{kg}$ BW, Janssen-Cilag Pharma). The animal's head was positioned and fixed in a Kopf stereotaxic frame (David Kopf Instruments). Infusions of the rAAV vectors were made through a 34-gauge stainless steel cannula (Cooper's Needle) fitted into a 5- $\mu$ L 5R-GPS SGE syringe (SGE Analytical Science Pty Ltd). Two micro-injections of $1 \mu \mathrm{L}$ and $0.5 \mu \mathrm{L}$ (of a $1: 1[\mathrm{v} / \mathrm{v}]$ mixture of the $\mathrm{rAAV}-5 / 2$ and $\mathrm{rAAV}-8 / 2$ vectors) were made per hemisphere, targeting the dorsal and ventral hippocampus, respectively. The coordinates targeting the dorsal and ventral hippocampus were based on the mouse brain stereotaxic atlas by Paxinos and Franklin (2001). The coordinates (anterior-posterior [AP] from Bregma, medio-lateral [ML] measured from midline of central sinus, and dorso-ventral [DV] from the dura surface] were as follows: $-2.0 \mathrm{~mm} \mathrm{AP}, \pm 1.7 \mathrm{~mm}$ $\mathrm{ML}$, and $-2.0 \mathrm{~mm}$ DV for the dorsal hippocampus; $-3.3 \mathrm{~mm} \mathrm{AP}$, $\pm 3.0 \mathrm{~mm} \mathrm{ML}$, and $-3.2 \mathrm{~mm}$ DV for the ventral hippocampus. A small hole was drilled through the skull before the cannula was inserted into the area of interest and left for $5 \mathrm{~min}$ before vector delivery. Stepwise delivery $(0.25 \mu \mathrm{L})$ of the viral vector was performed by retracting the cannula to $-1.4 \mathrm{~mm}$ (DV: dorsal) and $-2.6 \mathrm{~mm}$ (DV: ventral) in order to achieve optimal vector spread in the hippocampus. The vector was delivered manually at $0.2 \mu \mathrm{L} /$ min. At the end of infusion, the cannula was left in place for $2 \mathrm{~min}$, retracted $1 \mathrm{~mm}$, and left in place for an additional $3 \mathrm{~min}$ before being slowly withdrawn from the brain. Fifteen minutes post-surgery, the animals received a subcutaneous injection of antagonist in order to reverse the effects of the general anesthesia. The following mixture was diluted in $0.9 \%$ saline: Antisedan (Atipamezol, $0.75 \mathrm{mg} / \mathrm{kg} \mathrm{BW}$, Pfizer, Orion pharma), Anexate (Flumanezil, $0.2 \mathrm{mg} / \mathrm{kg} \mathrm{BW}$, Roche), and Naloxon (Narcan, $0.4 \mathrm{mg} / \mathrm{kg}$ BW, Swiss GmbH).

\section{Laser microdissection}

Immunofluorescently labeled coronal brain sections $(10 \mu \mathrm{m}$ thick) were mounted on gelatinized glass slides (Thermo Fisher Scientific) and kept in a moist chamber for subsequent laser microdissection. The slides were placed onto the stage of the PALM MicroBeam system (Zeiss). Epifluorescence microscopy was used to visualize EGFP-positive neurons using a $40 \times$ objective (NA 1.4). Individual cells were then outlined using the PALM RoboSoftware 3.2. graphic tools (as shown in Fig. 2B). A nitrogen $(337 \mathrm{~nm})$ laser, focused through the $40 \times$ objective lens, cut around (laser microdissection) and catapulted (pressure catapulting) (Fig. 2C) selected cells into the lid of a 0.5-mL capturing Microfuge tube (PALM, Zeiss). Following this, $25 \mu \mathrm{L}$ of distilled water was added to the lid, and the catapulted cells were transferred from the lid to the bottom of the Microfuge tube by brief centrifugation. A total of eight to 10 EGFP-positive cells from each treatment group (rAAV-EGFP and rAAV-EGFP-Cre) were collected for DNA isolation.

\section{PCR confirmation of gene deletion}

The isolated cells were subjected to genomic DNA extraction (QIAamp DNA Micro, QIAGEN) and subsequent nested PCR (Figs. 1A, 2D) (first-stage primer pair: MGEX9-I [forward]: 5'-CGGATGCTATGTGCAGTGCTGGA-3' and MGINII [reverse]: 5'-GAGAGAGATGGAGGGTCACTTGAG-3'; second-stage primer pair: 5 SynGAP1-1 [forward]: 5'-ATGTGCTGTGAGTTGGCC-3' and nested 3 SynGAP1 $n$ [reverse]: 5' -TATCTCACGGCCCTGG-3').

The presence of genomic DNA in all samples after LDM and LPC was confirmed by nested PCR as described above except that the first-stage forward primer MGEX9-I was replaced with a primer that binds within the SynGAP1 gene irrespective of its recombination status (loxDS: 5'-GAAGAGGAGTTTACGTCCAGCC AAGCT-3'). If no Cre-mediated recombination occurred, a weak diagnostic 1800-bp PCR product was detectable after the firststage PCR. Amplification of this weak signal during the secondstage PCR resulted in a strong 400-bp PCR product (Fig. 2D).

\section{Electrophysiology}

Mice were anesthetized with isofluorane and decapitated. Transversal hippocampal slices $(250 \mu \mathrm{m})$ were cut using a vibrating microtome (Leica). Slicing was done in an ice-cold solution containing $87 \mathrm{mM} \mathrm{NaCl}, 75 \mathrm{mM}$ sucrose, $25 \mathrm{mM}$ glucose, $25 \mathrm{mM} \mathrm{NaHCO}_{3}, 7 \mathrm{mM} \mathrm{MgCl}_{2}, 2.5 \mathrm{mM} \mathrm{KCl}, 1.25 \mathrm{mM} \mathrm{NaH}_{2} \mathrm{PO}_{4}$, and $0.5 \mathrm{mM} \mathrm{CaCl} 2$. After cutting, slices were incubated for $30 \mathrm{~min}$ at $35^{\circ} \mathrm{C}$ in artificial cerebrospinal fluid (ACSF), also used as extracellular solution for the experiments. The solution contained $125 \mathrm{mM} \mathrm{NaCl}, 26 \mathrm{mM} \mathrm{NaHCO}, 1.25 \mathrm{mM} \mathrm{NaH}_{2} \mathrm{PO}_{4}{ }^{*}$ $\mathrm{H}_{2} \mathrm{O}, 2.5 \mathrm{mM} \mathrm{KCl}, 1.0 \mathrm{mM} \mathrm{MgSO}{ }_{4}, 2.5 \mathrm{mM} \mathrm{CaCl} ; 310 \mathrm{mOsmol}$ and $\mathrm{pH} 7.4$ when bubbled with a gas mixture containing $95 \%$ $\mathrm{O}_{2}, 5 \% \mathrm{CO}_{2}$. Slices were carefully separated in injected and noninjected hemispheres. Whole-cell voltage-clamp $(-60 \mathrm{mV})$ recordings of spontaneous excitatory events (sEPSCs) were performed at $33^{\circ} \mathrm{C}$, using an internal solution containing $125 \mathrm{mM}$ $\mathrm{KMeSO}_{4}, 20 \mathrm{mM}$ HEPES, $14 \mathrm{mM}$ Tris-phosphocreatine, $5 \mathrm{mM}$ $\mathrm{Na}_{2}$-ATP, $5 \mathrm{mM} \mathrm{KCl}$, and $0.3 \mathrm{mM}$ Tris-GTP. Patch electrodes were pulled from borosilicate pipettes (5-7 M $\Omega$ tip resistance) on a horizontal puller (Zeitz). Currents were amplified using a Multiclamp $700 \mathrm{~A}$ amplifier (Axon Instruments), filtered at $10 \mathrm{kHz}$, and digitized at $20 \mathrm{kHz}$ (IGOR Pro). After recording, slices were immediately fixed in $4 \%$ paraformaldehyde, $15 \%$ saturated picric acid, and $0.1 \mathrm{M}$ phosphate buffer ( $\mathrm{pH} 7.4$ ) overnight at $4^{\circ} \mathrm{C}$, transferred to $20 \%$ sucrose and stored at $-20^{\circ} \mathrm{C}$ in cryoprotectant solution until post hoc immunohistochemical analyses (see below).

\section{Data analysis}

Analysis and filtering (at $2 \mathrm{kHz}$ ) of sEPSCs was performed by using the Mini Analysis Program (Synaptosoft, Version 6.0.3). Somatic recordings with an access resistance $>27 \mathrm{M} \Omega$ and a leak current $>200 \mathrm{pA}$ were excluded. Out of $10 \mathrm{~min}$ of recording time, the most stable 2-min period was taken for the analysis. sEPSCs were detected by the following search parameters: (gain, 15; blocks, 8;) threshold, 10-15 pA; period to search for a local maximum, $20 \mathrm{msec}$; time before a peak for baseline, $5 \mathrm{msec}$; period to search a decay time, 5 msec; fraction of peak to find a decay time, 0.5; period to average at baseline, 2 msec; area threshold, 913; number of points to average for peak, 3 ; direction of peak, negative. The significance of event intervals and amplitudes was calculated by a statistical comparison between ipsilateral and contralateral sides using the Kolmogorv-Smirnov-Test. Figures were created by using IGOR Pro software.

\section{Immunohistochemistry}

The mice were anesthetized with an overdose of sodium pentobarbital ( $40 \mathrm{mg} / \mathrm{kg} \mathrm{BW}$ [body weight]) and perfused transcardially with $4 \%$ phosphate-buffered paraformaldehyde solution containing $15 \%$ picric acid. The brains were removed and post-fixed in the same fixative for $3 \mathrm{~h}$. The brains were rinsed in phosphatebuffered saline (PBS, pH 7.4), cryoprotected in 30\% sucrose for $24 \mathrm{~h}$, and stored at $-80^{\circ} \mathrm{C}$. Sections ( $40 \mu \mathrm{m}$ thick) were cut coronally from frozen blocks with a sliding microtome, and 12 random sampled serial sections from Bregma $-0.8 \mathrm{~mm}$ to $-3.20 \mathrm{~mm}$ were collected, rinsed in PBS, and stored at $-20^{\circ} \mathrm{C}$ in cryoprotectant solution until further processing.

Before immunohistochemical staining, all brain sections were treated with pepsin (DAKO). Frozen aliquots containing $3 \mathrm{mg} / \mathrm{mL}$ pepsin solution in $0.2 \mathrm{~N} \mathrm{HCl}$ were thawed immediately 
before use and added to $0.2 \mathrm{~N} \mathrm{HCl}$ to a final pepsin concentration of $0.15 \mathrm{mg} / \mathrm{mL}$. Free-floating brain sections were incubated in pepsin solution for $10 \mathrm{~min}$ at $37^{\circ} \mathrm{C}$ and washed briefly in PBS.

For immunostaining, free-floating sections were rinsed three times for $10 \mathrm{~min}$ in Tris buffer (TBS, $50 \mathrm{mM}$ Tris, $150 \mathrm{mM} \mathrm{NaCl}$ at $\mathrm{pH}$ 7.4) containing $0.2 \%$ Triton $\mathrm{X}-100$ (TBST). The sections were then transferred in primary antibody diluted in TBST containing $2 \%$ normal goat serum (NGS) and incubated overnight in a moist chamber at $4^{\circ} \mathrm{C}$. The primary antibodies used in the study are depicted in Table 1.

\section{Fluorescence staining}

On the following day, the sections were rinsed three times (10 min each) in TBST, before they were incubated for $30 \mathrm{~min}$ in goatanti-rabbit or mouse Cy3 or Cy5 (1:500 each; Jackson ImmunoResearch Laboratories) diluted in TBST containing 2\% NGS. Following this, they were rinsed three times for $10 \mathrm{~min}$ each with PBS. They were mounted on gelatin-coated slides and allowed to air-dry for $30 \mathrm{~min}$. Finally, they were coverslipped with Dako fluorescent mounting medium (Dako).

\section{$D A B$ staining}

After three washes (each $10 \mathrm{~min}$ ) in TBST, the sections were incubated for $30 \mathrm{~min}$ at room temperature in biotinylated secondary antibody (1:300; Jackson ImmunoResearch) diluted in TBST containing $2 \%$ NGS. Sections were washed again three times (10 min each) in TBST and incubated in the Vectastain Kit (Vector Laboratories) diluted in TBST for $30 \mathrm{~min}$. After a further three washes in TBST, the sections were stained with 3,3-diaminobenzidine (DAB) and $0.05 \% \mathrm{H}_{2} \mathrm{O}_{2}$ for $8-20 \mathrm{~min}$ and rinsed again three times in PBS before mounting on gelatin-coated slides and dried overnight. Finally, they were dehydrated through an alcohol series, cleared with xylene, and coverslipped with Eukid (Kindler $\mathrm{GmbH})$.

\section{Microscopy}

Qualitative evaluation of immunofluorescence stainings was done with confocal microscopy (LSM-710, Zeiss) using either $10 \times($ NA 0.45$)$ for mosaic images, $40 \times($ NA1.3), or $63 \times$ plan apo-

Table 1. Summary of antibodies used for immunohistochemical staining (in alphabetical order)

\begin{tabular}{|c|c|c|c|}
\hline Antibody & Dilution & Manufacturer & Description/Nr \\
\hline $\begin{array}{l}\mathrm{GABA}_{\mathrm{A}} \text { receptor } \\
\alpha 1\end{array}$ & $1: 5000$ & $\begin{array}{l}\text { In-house (Fritschy } \\
\text { and Mohler 1995) }\end{array}$ & $\begin{array}{l}\text { Guinea pig } \\
\text { polyclonal a.p. }\end{array}$ \\
\hline $\begin{array}{l}\text { Activated } \\
\text { caspase-3 }\end{array}$ & $1: 3000$ & $\begin{array}{l}\text { Cell Signalling } \\
\text { Technology }\end{array}$ & $\begin{array}{l}\text { Rabbit polyclonal, } \\
\mathrm{Nr} 96615\end{array}$ \\
\hline AMPA GluR1 & $1: 2000$ & Millipore & $\begin{array}{l}\text { Rabbit polyclonal, } \\
\text { AB1504 }\end{array}$ \\
\hline $\begin{array}{l}\text { Cre } \\
\text { recombinase }\end{array}$ & $1: 4000$ & Covance & $\begin{array}{l}\text { Rabbit polyclonal, } \\
\text { PRB-106C }\end{array}$ \\
\hline $\begin{array}{l}\text { Doublecortin } \\
\text { (DCX) }\end{array}$ & $1: 1000$ & Millipore & $\begin{array}{l}\text { Guinea pig } \\
\text { polyclonal, } \\
\text { AB2253 }\end{array}$ \\
\hline GFAP & $1: 5000$ & DAKO Schweiz AG & $\begin{array}{l}\text { Rabbit polyclonal, } \\
\text { Z334 }\end{array}$ \\
\hline GFP & $1: 5000$ & Novus Biologicals Ltd & $\begin{array}{l}\text { Mouse } \\
\text { monoclonal, } \\
\text { NB600-597 }\end{array}$ \\
\hline Iba-1 & $1: 3000$ & $\begin{array}{l}\text { Wako Chemicals } \\
\text { GmbH }\end{array}$ & $\begin{array}{c}\text { Rabbit polyclonal, } \\
\text { Nr 01-1974 }\end{array}$ \\
\hline NMDA NR1 & $1: 1000$ & Millipore & $\begin{array}{l}\text { Rabbit polyclonal, } \\
\text { AB1516 }\end{array}$ \\
\hline SynGAP & $1: 3000$ & $A B R$ & $\begin{array}{l}\text { Rabbit polyclonal, } \\
\text { PA1-046 }\end{array}$ \\
\hline VGlut1 & $1: 5000$ & Millipore & $\begin{array}{l}\text { Guinea pig } \\
\text { polyclonal, } \\
\text { AB5905 }\end{array}$ \\
\hline
\end{tabular}

chromat objectives (NA 1.4) for high-magnification imaging. Double-fluorescence stainings were visualized using sequential acquisition of each channel. The pinhole aperture was set to 1.0 Airy unit for each channel. Stacks of consecutive optical sections $(12 ; 512 \times 512$ pixels, spaced $0.5 \mu \mathrm{m}$ in $z)$ were acquired at a magnification of $0.13 \mu \mathrm{m} /$ pixel. For visual display, Z-sections of all channels were projected in the $z$-dimension (maximal intensity), and merged using the image analysis software Imaris (Bitplane). Cropping of images and adjustments of brightness and contrast were identical for each labeling and done using Adobe Photoshop (CS3, Version 10.0.1, Adobe Systems).

\section{Quantification of GluA1- and NR1-positive clusters}

Quantitative analyses of the immunohistochemical stainings using anti-GluA1 and -NR1 antibodies were performed on a randomly selected hemisphere and performed blind to the viral expression construct (rAAV-EGFP controls, or rAAV-EGFP-Cre). Single stack digital images from four brain sections per animal were acquired from CA1 stratum radiatum, CA3 stratum radiatum and lucidum, and the DG molecular layer. The size, number, and sum pixel brightness of the GluA1- or NR1-immunoreactive clusters were quantified by segmentation of the binary images using a fixed threshold algorithm of ImageJ software (NIH; http://rsbweb. nih.gov/ij/).

\section{Optical densitometry}

Quantification of Iba-1 and SynGAP1 immunoreactivity was achieved by means of optical densitometry using ImageJ software. Digital images ( $n=4$ brain sections per sex and treatment) were acquired using an Axiocam MRc5 (Zeiss) digital camera mounted on a Zeiss Lumar V12 Stereomicroscope with a $0.8 \times$ NeoLumar S objective. Exposure time was held constant during acquisition of all images. Pixel brightness was measured on one randomly selected hemisphere in the outlined subregions of the hippocampus (DG molecular layer, CA1 stratum radiatum, CA3 stratum radiatum and lucidum, CA4 stratum radiatum), as well as in the corpus callosum, which served as background area. The backgroundcorrected pixel brightness was averaged per brain region and animal.

\section{Counting of Doublecortin (DCX)-positive neurons}

DCX-positive cells in the dentate gyrus subgranular zone were counted exhaustively on both hemispheres of four to five sections per animal using live microscopy with a $40 \times$ objective (NA 1.3). The cells counted were averaged per hemisphere and animal.

\section{Behavioral experiments}

\section{Elevated plus maze test}

The elevated plus maze test exploits the approach-avoidance conflict, which involves the natural tendency of rodents to explore a novel environment and the aversive properties of an open area (Handley and Mithani 1984). The apparatus was made of opaque Plexiglas with a removable plastic gray floor as described previously (Hagenbuch et al. 2006). It consisted of four interconnected elevated stem arms $(30 \mathrm{~cm}$ long $\times 5 \mathrm{~cm}$ wide) radiating from a central square measuring $5 \times 5 \mathrm{~cm}$ and raised $\sim 70 \mathrm{~cm}$ above the floor. The maze was positioned in the middle of the experimental room with diffuse dim lighting (25 lux in the center of the maze). One pair of opposing arms was enclosed with a perimeter wall made of opaque Plexiglas (14 cm high); the other pair of opposing arms was exposed. Here, the test session lasted $5 \mathrm{~min}$, during which the animals were allowed to explore the maze freely before being removed and returned to the home cage. The following measures were recorded using the Ethovision (Noldus Technology) tracking system: (1) Percentage frequency of entries made to the open arms $=($ entries into open arms/entries into all arms $\times 100 \%)$, (2) Percentage time spent in the open arms = (time in open arms/time in all arms $\times 100 \%$ ), and (3) distance traveled in the maze during the 5-min session. 


\section{Spontaneous open field activity}

The open field and the procedure have been previously described (Hauser et al. 2005). Each subject was gently placed in the center of the open field and allowed to explore freely for $60 \mathrm{~min}$. Locomotor activity was indexed by the distance moved (in meters) across successive 10-min bins.

\section{Spatial novelty preference test}

Spatial recognition memory was evaluated by spontaneous alternation task in the Y-maze in accordance with Sanderson et al. (2007) and Bannerman et al. (2008). This task assessed short-term spatial memory and uses the natural tendency for rodents to explore novel over familiar spatial environments. The procedure was performed in a Y-maze elevated $90 \mathrm{~cm}$ above the floor and positioned in the middle of a dimly lit (30 lux in the center of the maze) experiment room. A digital camera mounted above the maze captured images at a rate of $5 \mathrm{~Hz}$, which were then transmitted to a PC running the Ethovision tracking system (Noldus Technology).

\section{Apparatus}

The apparatus was made of transparent Plexiglas and consisted of three identical arms $(50 \mathrm{~cm} \times 9 \mathrm{~cm}$; length $\times$ width $)$ surrounded by $10-\mathrm{cm}$-high transparent Plexiglas walls. The three arms radiated from a central triangle $\left(8 \mathrm{~cm}\right.$ on each side) and spaced $120^{\circ}$ from each other. Access to each arm from the central area could be blocked by a removable opaque barrier wall. The floor of the maze was covered with sawdust bedding, which was changed between testing phases as well as between trials. Three identical Y-mazes, each housed in a distinct testing room, were used here for each retention interval tested (see later). In addition, testing was performed in three different experimental rooms, each containing a unique set of extra-maze cues. The allocation of arms (start, familiar and novel arm) to a specific spatial location was counterbalanced across subjects.

\section{Sample phase}

The subjects were assigned two arms (start arm and familiar arm) to which they were exposed during this phase. Access to the remaining arm (novel arm) was blocked by a barrier wall door. The subject was introduced at the end of the start arm, facing the central triangle and allowed to freely explore both the start and familiar arms for $5 \mathrm{~min}$. Testing time was initiated once the subject had made an entry into the central triangular area, as detected by the Ethovision tracking system. The subject was then removed and kept in a holding cage for 2 min ( 0 min delay) or returned to the home cage for the 15 -min or 1-h retention intervals before the test phase. The barrier door was removed and the sawdust flooring changed to avoid olfactory cues.

\section{Test phase}

The remaining third arm constituted the novel arm during this phase. Following the retention interval, the test subject was introduced to the maze, with the barrier wall removed, and allowed to freely explore the maze for $3 \mathrm{~min}$. The subject was then removed from the maze and returned to its home cage. The sawdust flooring was changed in preparation for the next trial. On each trial, the time spent in each of the three arms was recorded for both the sample and test phases. For the test phase, the percentage time spent in the novel arm- [(time in the novel arm)/(time in the novel + time in familiar arm) $] \times 100 \%$-was calculated as an index for spatial novelty preference.

\section{Morris water maze test: reference memory and reversal learning}

Spatial reference memory and reversal learning were evaluated in the Morris water maze task. The water maze consisted of a circular tank made of white fiberglass. It measured $1 \mathrm{~m}$ in diameter and was filled daily with fresh tap water maintained at $22^{\circ} \mathrm{C} \pm 2{ }^{\circ} \mathrm{C}$.
Four equally spaced cardinal points (N, S, E, and W) were designated on the circumference of the pool and served as the starting points, from which the animals were released facing the wall of the water maze. A solid cylinder made of transparent Plexiglas (diameter $7 \mathrm{~cm}$, height $18.5 \mathrm{~cm}$ ) served as the escape platform and was submerged beneath the water surface to a depth of $1.5 \mathrm{~cm}$, and therefore invisible to the animals. The maze was positioned in the middle of a dimly lit (80 lux on the water surface) experimental room that was equipped with several extra-maze cues. Automated swim path monitoring was provided by the Ethovision tracking system (Noldus Technology).

\section{Visible platform training}

On day 1 , the mice were tested on four consecutive trials (ITI $=$ $1 \mathrm{~min}$ ) in the cued version of the task to find a submerged platform that was indicated by a salient local cue visible above the water level. This was performed to assess the general motivation to escape from water and rule out any visual or motor deficits. The escape platform was positioned in the center of the water maze, and the starting positions were varied randomly among the four possible starting points (S, E, N, and $\mathrm{W})$. A trial ended when an animal escaped onto the platform or when $60 \mathrm{sec}$ had elapsed, after which the animal would be guided to the platform by the experimenter. The animals were allowed to spend $30 \mathrm{sec}$ on the platform and then placed into a waiting cage for a further $30 \mathrm{sec}$ before the next trial began.

\section{Hidden platform training}

On days $2-8$, the animals were trained to locate the escape platform ( $7 \mathrm{~cm}$ in diameter) submerged $1 \mathrm{~cm}$ below the water surface in a constant location (middle of SE quadrant). The starting positions were varied in a pseudorandom sequence across two trials, with $\mathrm{N}, \mathrm{E}, \mathrm{S}$, and $\mathrm{W}$ each being used once. The variables used to determine performance in the task included escape latency (in seconds) and distance swum to reach the platform (in centimeters).

\section{Probe test 1}

On day 9, a 60-sec probe test was conducted with the platform removed from the water maze and with the starting position (NW) for all subjects. Performance was evaluated by percent distance and time spent in the target quadrant in comparison with the other quadrants.

\section{Reversal learning}

Reversal learning was performed from days 10 to 15 . The hidden platform was shifted to the middle of the opposite quadrant (NW), and training was performed as described in the reference memory subsection.

\section{Probe test 2}

Following reversal training, a 60 -sec probe test was performed on day 16 as described before. The starting position (SE) was constant for all subjects.

\section{Statistical analysis}

In the behavioral experiments, data were subjected to parametric analysis of variance (ANOVA), with between-subject factors: Treatment (rAAV-EGFP vs. rAAV-EGFP-Cre) and Sex (male vs. female). The following repeated measures (within-subjects) factors as appropriated by the design of the experiment included Bins, Delays, or Days. These were supplemented by restricted ANOVAs whenever appropriate to aid the interpretation of complex interaction effects stemming from the overall multi-factorial ANOVA. In addition, Fisher's LSD pairwise comparisons were implemented to examine significant main effects as well as interaction terms. A two-tailed Type I error rate of $P<0.05$ was adopted as the yardstick for statistical significance. For immunohistochemical 
analysis, the Kolmogorov-Smirnov non-parametric analysis was performed to determine cluster size distribution of GluR1- and NR1-immunoreactive puncta. An independent Student's $t$-test was used for statistical comparison between treatment groups for the anti-Iba1 and SynGAP1 densitometrical analysis. All analyses were performed using SPSS for Windows (version 19, SPSS Inc.) implemented on a PC running the Windows XP (SP2) operating system.

\section{Acknowledgments}

This study was supported by the Swiss Federal Institute of Technology Zurich, Grant Nr TH-22a/04-03 and SNF Grant Nr 310000-117806 (IK). We thank Corinne Sidler (Institute of Pharmacology and Toxicology, University of Zurich) for her help with the immunohistochemical stainings. We also thank Dr. Oleg Georgiev (Institute of Molecular Life Sciences, University of Zurich) for providing the Klenow-blunted SalI-NLS Cre-XbaI fragment of pCMV-NLS Cre. We are grateful to Jean-Marc Fritschy for his invaluable advice and support. We also thank the Animal Services Department Schwerzenbach for animal husbandry and care and Dr. Frank Bootz for his veterinary expertise and supervision.

\section{References}

Ahmed BY, Chakravarthy S, Eggers R, Hermens WT, Zhang JY, Niclou SP, Levelt C, Sablitzky F, Anderson PN, Lieberman AR, et al. 2004. Efficient delivery of Cre-recombinase to neurons in vivo and stable transduction of neurons using adeno-associated and lentiviral vectors. BMC Neurosci 5: 4. doi: $10.1186 / 1471-2202-5-4$.

Aimone JB, Deng W, Gage FH. 2010. Adult neurogenesis: Integrating theories and separating functions. Trends Cogn Sci 14: 325-337.

Bannerman DM, Grubb M, Deacon RM, Yee BK, Feldon J, Rawlins JN. 2003. Ventral hippocampal lesions affect anxiety but not spatial learning. Behav Brain Res 139: 197-213.

Bannerman DM, Rawlins JN, McHugh SB, Deacon RM, Yee BK, Bast T, Zhang WN, Pothuizen HH, Feldon J. 2004. Regional dissociations within the hippocampus-memory and anxiety. Neurosci Biobehav Rev 28: $273-283$.

Bannerman DM, Niewoehner B, Lyon L, Romberg C, Schmitt WB, Taylor A, Sanderson DJ, Cottam J, Sprengel R, Seeburg PH, et al. 2008. NMDA receptor subunit NR2A is required for rapidly acquired spatial working memory but not incremental spatial reference memory. J Neurosci 28: 3623-3630.

Barnett MW, Watson RF, Vitalis T, Porter K, Komiyama NH, Stoney PN, Gillingwater TH, Grant SG, Kind PC. 2006. Synaptic Ras GTPase activating protein regulates pattern formation in the trigeminal system of mice. J Neurosci 26: 1355-1365.

Bast T, Feldon J. 2003. Hippocampal modulation of sensorimotor processes. Prog Neurobiol 70: 319-345.

Carlisle HJ, Manzerra P, Marcora E, Kennedy MB. 2008. SynGAP regulates steady-state and activity-dependent phosphorylation of cofilin. J Neurosci 28: 13673-13683.

Chen HJ, Rojas-Soto M, Oguni A, Kennedy MB. 1998. A synaptic Ras-GTPase activating protein (p135 SynGAP) inhibited by CaM kinase II. Neuron 20: 895-904.

Couillard-Despres S, Winner B, Schaubeck S, Aigner R, Vroemen M, Weidner N, Bogdahn U, Winkler J, Kuhn HG, Aigner L. 2005. Doublecortin expression levels in adult brain reflect neurogenesis. Eur J Neurosci 21: 1-14.

Deacon RM, Bannerman DM, Rawlins JN. 2002. Anxiolytic effects of cytotoxic hippocampal lesions in rats. Behav Neurosci 116: 494-497.

Di Pasquale G, Davidson BL, Stein CS, Martins I, Scudiero D, Monks A, Chiorini JA. 2003. Identification of PDGFR as a receptor for AAV-5 transduction. Nat Med 9: 1306-1312.

Elgersma Y, Fedorov NB, Ikonen S, Choi ES, Elgersma M, Carvalho OM, Giese KP, Silva AJ. 2002. Inhibitory autophosphorylation of CaMKII controls PSD association, plasticity, and learning. Neuron 36: 493-505.

Engelhardt von J, Doganci B, Jensen V, Hvalby Ø, Göngrich C, Taylor A, Barkus C, Sanderson DJ, Rawlins JN, Seeburg PH, et al. 2008. Contribution of hippocampal and extra-hippocampal NR2Bcontaining NMDA receptors to performance on spatial learning tasks. Neuron 60: 846-860.

Fritschy JM, Mohler H. 1995. GABAA-receptor heterogeneity in the adult rat brain: Differential regional and cellular distribution of seven major subunits. J Comp Neurol 359: 154-194.

Gao C, Frausto SF, Guedea AL, Tronson NC, Jovasevic V, Leaderbrand K, Corcoran KA, Guzmán YF, Swanson GT, Radulovic J. 2011. IQGAP1 regulates NR2A signaling, spine density, and cognitive processes. $J$ Neurosci 31: 8533-8842.

Garthe A, Behr J, Kempermann G. 2009. Adult-generated hippocampal neurons allow the flexible use of spatially precise learning strategies. PLOS ONE 4: e5464. doi: 10.1371/journal.pone.0005464.

Glass MJ, Hegarty DM, Oselkin M, Quimson L, South SM, Xu Q, Pickel VM, Inturrisi CE. 2008. Conditional deletion of the NMDA-NR1 receptor subunit gene in the central nucleus of the amygdala inhibits naloxone-induced conditioned place aversion in morphine-dependent mice. Exp Neurol 213: 57-70.

Gray JA. 1982. The neuropsychology of anxiety: An enquiry into the functions of the septo-hippocampal system. Oxford University Press, New York.

Gray JA, McNaughton N. 1983. Comparison between the behavioral effects of septal and hippocampal lesions: A review. Neurosci Biobehav Rev 7: 119-188.

Guo X, Hamilton PJ, Reish NJ, Sweatt JD, Miller CA, Rumbaugh G. 2009. Reduced expression of the NMDA receptor-interacting protein SynGAP causes behavioral abnormalities that model symptoms of schizophrenia. Neuropsychopharmacol 34: 1659-1672.

Hagenbuch N, Feldon J, Yee BK. 2006. Use of the elevated plus-maze with opaque or transparent walls in the detection of mouse strain differences and the anxiolytic effects of diazepam. Behav Pharmacol 17: 31-41.

Handley SL, Mithani S. 1984. Effects of $\alpha$-adrenoceptor agonists and antagonists in a maze-exploration model of 'fear'-motivated behavior. Naunyn Schmiedebergs Arch Pharmacol 327: 1-5.

Hauser J, Rudolph U, Keist R, Möhler H, Feldon J, Yee BK. 2005. Hippocampal alpha5 subunit-containing GABAA receptors modulate the expression of prepulse inhibition. Mol Psychiatry 10: 201-207.

Huang EJ, Reichardt LF. 2003. Trk receptors: Roles in neuronal signal transduction. Annu Rev Biochem 72: 609-642.

Inturrisi CE. 2005. The role of $N$-methyl-D-aspartate (NMDA) receptors in pain and morphine tolerance. Minerva Anestesiol 71: 401-403.

Kaplan DR, Miller FD. 2000. Neurotrophin signal transduction in the nervous system. Curr Opin Neurobiol 10: 381-391.

Kaspar BK, Vissel B, Bengoechea T, Crone S, Randolph-Moore L, Muller R, Brandon EP, Schaffer D, Verma IM, Lee KF, et al. 2002. Adeno-associated virus effectively mediates conditional gene modification in the brain. Proc Natl Acad Sci 99: 2320-2325.

Kennedy MB. 1997. The postsynaptic density at glutamatergic synapses. Trends Neurosci 20: 264-268.

Kennedy MB. 2000. Signal-processing machines at the postsynaptic density. Science 290: 750-754.

Kim JH, Liao D, Lau LF, Huganir RL. 1998. SynGAP: A synaptic RasGAP that associates with the PSD-95/SAP90 protein family. Neuron 20: 683-691.

Kim JH, Lee HK, Takamiya K, Huganir RL. 2003. The role of synaptic GTPase-activating protein in neuronal development and synaptic plasticity. J Neurosci 23: 1119-1124.

Knuesel I, Elliott A, Chen HJ, Mansuy IM, Kennedy MB. 2005. A role for synGAP in regulating neuronal apoptosis. Eur J Neurosci 21: 611-621.

Komiyama NH, Watabe AM, Carlisle HJ, Porter K, Charlesworth P, Monti J, Strathdee DJ, O'Carroll CM, Martin SJ, Morris RG, et al. 2002. SynGAP regulates ERK/MAPK signaling, synaptic plasticity, and learning in the complex with postsynaptic density 95 and NMDA receptor. J Neurosci 22: $9721-9732$.

Krapivinsky G, Medina I, Krapivinsky L, Gapon S, Clapham DE. 2004. SynGAP-MUPP1-CaMKII synaptic complexes regulate p38 MAP kinase activity and NMDA receptor-dependent synaptic AMPA receptor potentiation. Neuron 43: 563-574.

Lee N, Robitz R, Zurbrugg RJ, Karpman AM, Mahler AM, Cronier SA, Vesey R, Spearry RP, Zolotukhin S, Maclennan AJ. 2008. Conditional, genetic disruption of ciliary neurotrophic factor receptors reveals a role in adult motor neuron survival. Eur J Neurosci 27: 2830-2837.

Morris RG, Garrud P, Rawlins JN, O'Keefe J. 1982. Place navigation impaired in rats with hippocampal lesions. Nature 297: 681-683.

Morris R, Anderson E, Lynch GS, Baudry M. 1986. Selective impairment of learning and blockade of long-term potentiation by an $N$-methylD-aspartate receptor antagonist, AP5. Nature 319: 774-776.

Muhia M, Feldon J, Knuesel I, Yee BK. 2009. Appetitively motivated instrumental learning in SynGAP heterozygous knockout mice. Behav Neurosci 123: 1114-1128.

Muhia M, Yee BK, Feldon J, Markopoulos F, Knuesel I. 2010. Disruption of hippocampus-regulated behavioural and cognitive processes by heterozygous constitutive deletion of SynGAP. Eur J Neurosci 31 : 529-543.

Nakazawa K, Quirk MC, Chitwood RA, Watanabe M, Yeckel MF, Sun LD, Kato A, Carr CA, Johnston D, Wilson MA, et al. 2002. Requirement for hippocampal CA3 NMDA receptors in associative memory recall. Science 297: 211-218.

Nakazawa K, Sun LD, Quirk MC, Rondi-Reig L, Wilson MA, Tonegawa S. 2003. Hippocampal CA3 NMDA receptors are crucial for memory acquisition of one-time experience. Neuron 38: 305-315. 
Niewoehner B, Single FN, Hvalby O, Jensen V, Meyer zum Alten Borgloh S, Seeburg PH, Rawlins JN, Sprengel R, Bannerman DM. 2007. Impaired spatial working memory but spared spatial reference memory following functional loss of NMDA receptors in the dentate gyrus. Eur J Neurosci 25: $837-846$.

Oh JS, Manzerra P, Kennedy MB. 2004. Regulation of the neuron-specific Ras GTPase-activating protein, SynGAP, by $\mathrm{Ca}^{2+} /$ calmodulindependent protein kinase II. J Biol Chem 279: 17980-17988.

Paterna JC, Bueler H. 2002. Recombinant adeno-associated virus vector design and gene expression in the mammalian brain. Methods 28: 208-218.

Paterna JC, Moccetti T, Mura A, Feldon J, Bueler H. 2000. Influence of promoter and WHV post-transcriptional regulatory element on AAVmediated transgene expression in the rat brain. Gene Ther 7: 13041311.

Paterna JC, Feldon J, Bueler H. 2004. Transduction profiles of recombinant adeno-associated virus vectors derived from serotypes 2 and 5 in the nigrostriatal system of rats. J Virol 78: 6808-6817.

Paterna JC, Leng A, Weber E, Feldon J, Bueler H. 2007. DJ-1 and Parkin modulate dopamine-dependent behavior and inhibit MPTP-induced nigral dopamine neuron loss in mice. Mol Ther 15: 698-704.

Paxinos G, Franklin KB. 2001. The mouse brain in stereotaxic coordinates, 2nd ed. Elsevier Academic Press, Amsterdam.

Pena V, Hothorn M, Eberth A, Kaschau N, Parret A, Gremer L, Bonneau F, Ahmadian MR, Scheffzek K. 2008. The C2 domain of SynGAP is essential for stimulation of the Rap GTPase reaction. EMBO Rep 9: 350-355.

Pietropaolo S, Paterna JC, Bueler H, Feldon J, Yee BK. 2007. Bidirectional changes in water-maze learning following recombinant adenovirusassociated viral vector (rAAV)-mediated brain-derived neurotrophic factor expression in the rat hippocampus. Behav Pharmacol 18: 533-547.

Pothuizen HH, Zhang WN, Jongen-Relo AL, Feldon J, Yee BK. 2004.

Dissociation of function between the dorsal and the ventral

hippocampus in spatial learning abilities of the rat: A within-subject, within-task comparison of reference and working spatial memory. Eur J Neurosci 19: 705-712.

Pouzet B, Welzl H, Gubler MK, Broersen L, Veenman CL, Feldon J, Rawlins JN, Yee BK. 1999. The effects of NMDA-induced retrohippocampal lesions on performance on four spatial memory tasks known to be sensitive to hippocampal damage in the rat. Eur J Neurosci 11: $123-140$.

Rama S, Krapivinsky G, Clapham DE, Medina I. 2008. The MUPP1-SynGAP $\alpha$ protein complex does not mediate activity-induced LTP. Mol Cell Neurosci 38: $183-188$.

Rumbaugh G, Adams JP, Kim JH, Huganir RL. 2006. SynGAP regulates synaptic strength and mitogen-activated protein kinases in cultured neurons. Proc Natl Acad Sci 103: 4344-4351.

Rust MB, Gurniak CB, Renner M, Vara H, Morando L, Görlich A, Sassoe-Pognetto M, Bachaabouchi MA, Giustetto M, Triller A, et al. 2010. Learning, AMPA receptor motility and synaptic plasticity depend on n-colfilin-mediated actin dynamics. EMBO J 29: 1889-1902.

Sanderson DJ, Gray A, Simon A, Taylor AM, Deacon RM, Seeburg PH, Sprengel R, Good MA, Rawlins JN, Bannerman DM. 2007. Deletion of glutamate receptor-A (GluR-A) AMPA receptor subunits impairs one-trial spatial memory. Behav Neurosci 121: 559-569.

Scammell TE, Arrigoni E, Thompson MA, Ronan PJ, Saper CB, Greene RW. 2003. Focal deletion of the adenosine A1 receptor in adult mice using an adeno-associated viral vector. J Neurosci 23: 5762-5770.

Vazquez LE, Chen HJ, Sokolova I, Knuesel I, Kennedy MB. 2004. SynGAP regulates spine formation. J Neurosci 24: 8862-8872.

Zolotukhin S, Byrne BJ, Mason E, Zolotukhin I, Potter M, Chesnut K, Summerford C, Samulski RJ, Muzyczka N. 1999. Recombinant adeno-associated virus purification using novel methods improves infectious titer and yield. Gene Ther 6: 973-985.

Received March 13, 2012; accepted in revised form April 12, 2012. 


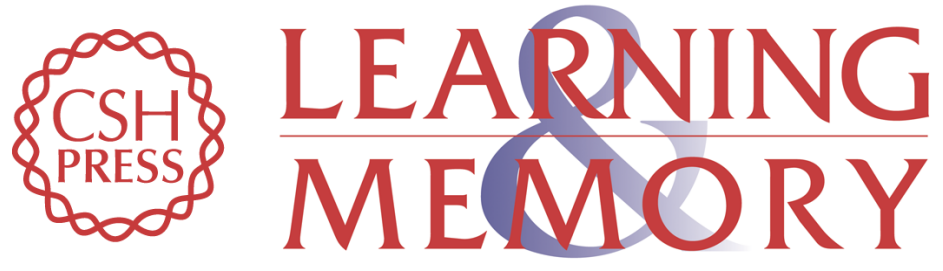

\section{Molecular and behavioral changes associated with adult hippocampus-specific SynGAP1 knockout}

Mary Muhia, Silvia Willadt, Benjamin K. Yee, et al.

Learn. Mem. 2012, 19:

Access the most recent version at doi:10.1101/lm.026351.112

References This article cites 58 articles, 14 of which can be accessed free at: http://learnmem.cshlp.org/content/19/7/268.full.html\#ref-list-1

License

Email Alerting Receive free email alerts when new articles cite this article - sign up in the box at the Service top right corner of the article or click here. 